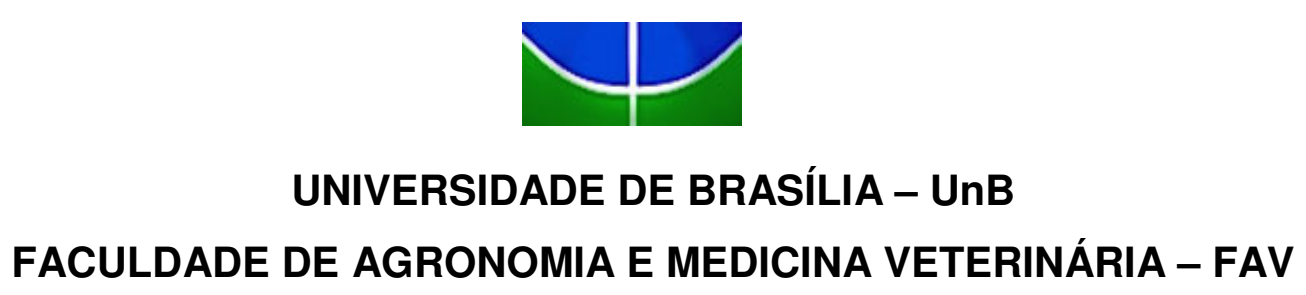

INFLUÊNCIA DO NITROGÊNIO NA FENOLOGIA DA CEVADA (Hordeum vulgare L.) CERVEJEIRA IRRIGADA NO CERRADO.

Vítor Antunes Monteiro

MONOGRAFIA DE GRADUAÇÃO EM AGRONOMIA

BRASÍLIA - DF

1ㅇ SEMESTRE/2009 


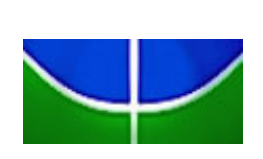

UNIVERSIDADE DE BRASÍLIA - UnB

FACULDADE DE AGRONOMIA E MEDICINA VETERINÁRIA - FAV

\title{
INFLUÊNCIA DO NITROGÊNIO NA FENOLOGIA DA CEVADA (Hordeum vulgare L.) CERVEJEIRA IRRIGADA NO CERRADO.
}

Vítor Antunes Monteiro

\begin{abstract}
Projeto final de Estágio Supervisionado, submetido à Faculdade de Agronomia e Medicina Veterinária da Universidade de Brasília, como requisito parcial para a obtenção do grau de Engenheiro Agrônomo.
\end{abstract}

APROVADO PELA BANCA EXAMINADORA:

José Alencar Carneiro de Freitas

Eng. Agr., M. Sc. em Agronomia, professor da FAV/UnB

Orientador

Renato Fernando Amabile

Eng. Agr., M. Sc. em Agronomia, pesquisador da Embrapa Cerrados Orientador

Lucian Ricardo Guedes Fidelis

Eng. Agr.

Examinador 
Monteiro, Vítor Antunes

Influência do nitrogênio na fenologia da cevada

(Hordeum vulgare L.) cervejeira irrigada no Cerrado. /

Vitor Antunes Monteiro; Renato Fernando Amabile -

Brasília, 2009.

$\mathbf{x x}$ p. : il.

Monografia - Universidade de Brasília / Faculdade de Agronomia e Medicina Veterinária, 2009.

\section{CESSÃo de diREITOS}

Nome do Autor: Vítor Antunes Monteiro.

Título da Monografia de Conclusão de Curso: Influência do nitrogênio na fenologia da cevada (Hordeum vulgare L.) cervejeira irrigada no Cerrado.

Ano: 2009

É concedida à Universidade de Brasília permissão para reproduzir cópias desta monografia e para emprestar ou vender tais cópias somente para propósitos acadêmicos e científicos. O autor reserva-se a outros direitos de publicação e nenhuma parte desta monografia pode ser reproduzida sem a autorização por escrito do autor.

Vítor Antunes Monteiro 


\section{AGRADECIMENTOS}

Primeiramente a Deus, por todas as oportunidades que me foram oferecidas durante meu caminho.

Aos meus pais, José Roberto e Leila, ao meu irmão, José Henrique, aos meus avós paternos, José e Dilma, e à minha avó materna, Vanda, por todo o apoio e carinho que me deram em todos os momentos da minha vida.

A minha namorada Desirée, por todo o amor, carinho, apoio, incentivo e paciência, e a toda a sua família, pelos votos de confiança.

Ao meu orientador de estágio na Embrapa Cerrados Renato Fernando Amabile, por todo o conhecimento transmitido, pela amizade e pela oportunidade de estágio.

Aos meus bons amigos remanescentes do ensino médio, pela amizade, apoio e pelas risadas nos momentos mais difíceis.

Aos queridos amigos da UnB e mestres, que estiveram comigo durante esses cinco anos de estudo; aos meus companheiros de estágio e aos funcionários da Embrapa Cerrados, especialmente ao Amiltinho, que sempre se prontificaram em me ajudar no campo e nos laboratórios.

A todos estes, meu sincero muito obrigado pela contribuição em minha formação como Engenheiro Agrônomo. 
INFLUÊNCIA DO NITROGÊNIO NA FENOLOGIA DA CEVADA (Hordeum vulgare L.) CERVEJEIRA IRRIGADA NO CERRADO.

RESUMO - Foi conduzido no campo experimental da Embrapa Cerrados (PlanaltinaDF) um ensaio utilizando seis genótipos de cevada (Hordeum vulgare L.), AF 9585, CEV 98074, LACEY, Prestige, BRS 180 e BRS 195, em quatro doses de nitrogênio com três repetições. Foram avaliados os estádios fisiológicos em função das doses $0 \mathrm{~N}, 20 \mathrm{~N}, 40 \mathrm{~N}$ e $80 \mathrm{~N}$, bem como os graus-dia da emergência ao espigamento. $\mathrm{O}$ nitrogênio influencia no surgimento das fases fenológicas e no ciclo da planta, aumentando-o ou diminuindo-o em função da dose apregoada.

Palavras-chave: 1. Cevada; 2. Hordeum vulgare L.; 3. Nitrogênio; 4. Fenologia; 5. Cerrado. 
THE INFLUENCE OF NITROGEN ON IRRIGATED BEER BARLEY FENOLOGY (Hordeum vulgare L.) IN SAVANNAH

ABSTRACT - Was conduced on experimental camp of Embrapa Cerrados (PlanaltinaDF) a test using six genotypes of barley (Hordeum vulgare L.), AF 9585, CEV 98074 , LACEY, Prestige, BRS 180 e BRS 195, in four nitrogen doses with three repetitions. Were evaluated the fenological stages in function of doses $0 \mathrm{~N}, 20 \mathrm{~N}, 40 \mathrm{~N}$ and $80 \mathrm{~N}$, as well as the degree-days of emergency until heading. Nitrogen influenced the appearing of fenological stages and plant cycle, increasing it or decreasing it in function of the dose used.

Key-words: 1. Barley; 2. Hordeum vulgare L.; 3. Nitrogen; 4. Fenology; 5. Savannah. 


\section{SUMÁRIO}

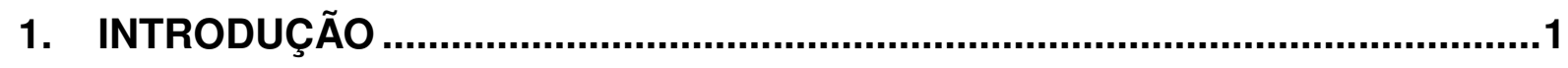

2. OBJETIVO

3. REVISÃO BIBLIOGRÁFICA

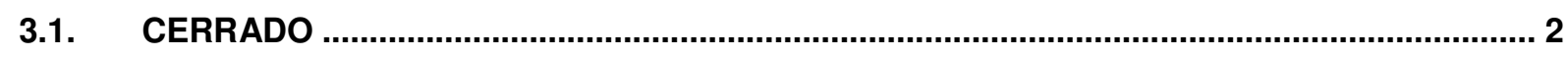

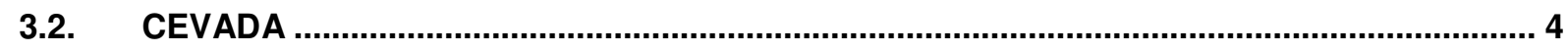

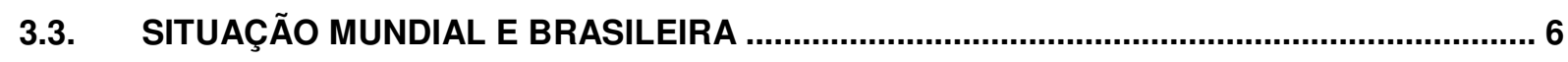

3.4. NITROGÊNIO ........................................................................................................

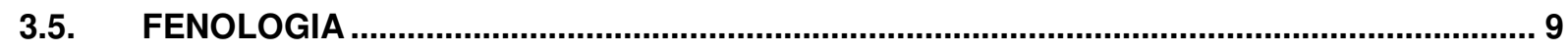

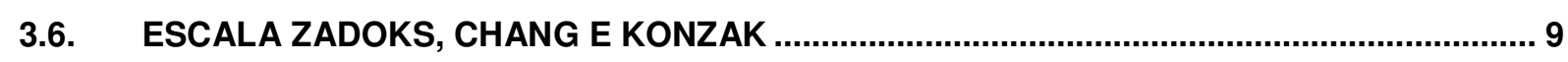

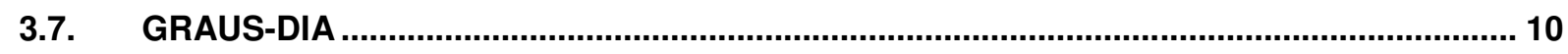

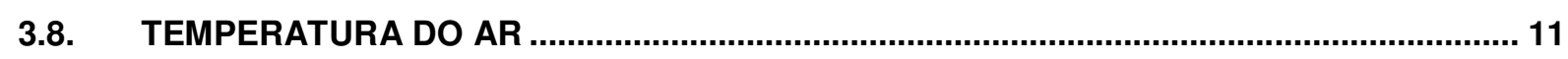

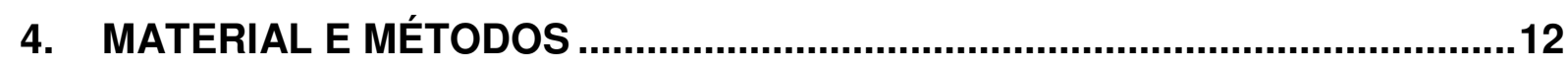

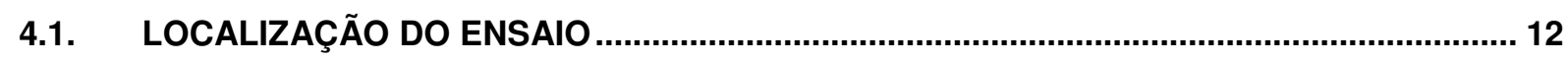

4.2. CARACTERÍSTICAS DO ENSAIO ........................................................................... 13

4.3. OBTENÇÃO DE DADOS ................................................................................... 14

4.3.1. VARIÁVEIS CLIMÁTICAS............................................................................... 14

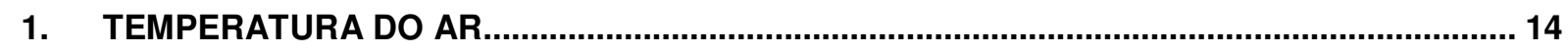

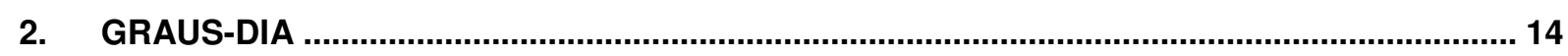

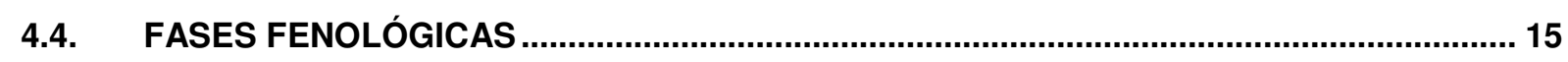

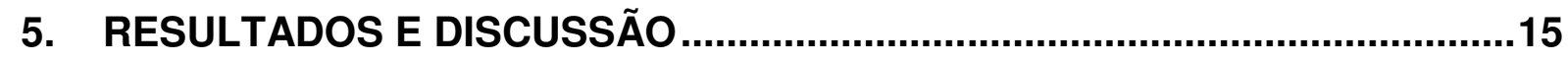

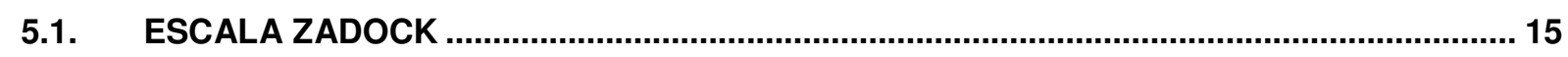

5.2. INFLUÊNCIA DA ADUBAÇÃO NITROGENADA NOS ESTÁDIOS FENOLÓGICOS ........... 17

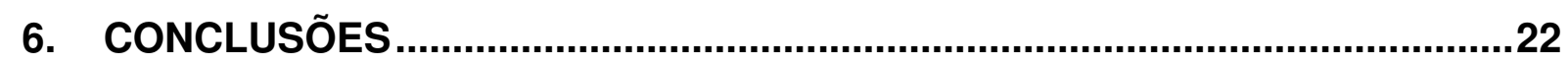

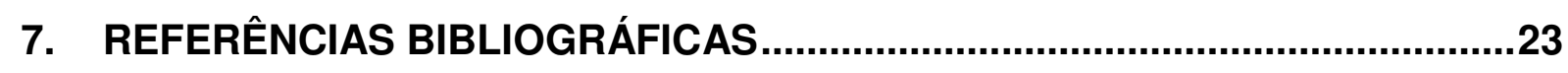

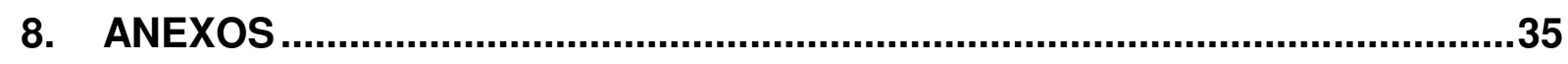




\section{INTRODUÇÃO}

A cevada (Hordeum vulgare L.) foi uma das primeiras plantas domesticadas pelo homem. Seu centro de origem é região do Oriente Médio, sendo China e Etiópia considerados centros secundários da cultura (Harlan, 1979). Ela vem se mantendo como um dos grãos mais produzidos no mundo, devido principalmente à sua grande capacidade de adaptação, tanto para uso na alimentação humana, animal ou na produção de malte.

A cevada é produzida comercialmente desde 1930 no Brasil (Minella, 1999a). A indústria malteira determina a produção, sendo responsável por absorver $85 \%$ de toda a colheita. Os 15\% restantes são utilizados na alimentação humana e no plantio, como semente (Amabile et al., 2004a). Ainda que o país utilize praticamente toda a produção nacional do cereal, faz-se necessário a sua importação, como malte, de aproximadamente $80 \%$ (Fagundes, 2003). De janeiro a dezembro de 2006, segundo dados da CONAB (2008), a quantidade de malte importado esteve na ordem de 751 mil toneladas, causando um prejuízo de aproximadamente 218 milhões de dólares para a balança comercial, colocando o país como um dos maiores importadores de malte do mundo.

Anteriormente, a cevada era plantada apenas na região Sul do Brasil, por tratar-se de uma cultura originalmente de clima temperado. Porém, essa região apresenta alguns aspectos limitantes à cultura como clima apropriado ao desenvolvimento de doenças; ocorrência de geadas comprometendo a produção; chuvas após a maturação fisiológica do grão, reduzindo sua qualidade; e competição com outros cereais de inverno, como o trigo.

Com a crescente demanda de cevada no país, por parte das indústrias malterias, a introdução de novos genótipos na região do Cerrado brasileiro foi inevitável. O cultivo irrigado da cevada no Cerrado foi iniciado no ano de $1976 \mathrm{com}$ o lançamento do Plano Nacional de Auto-suficiência de Cevada e Malte - PLANACEM e o início dos ensaios nacionais, com o apoio da Embrapa e de algumas companhias cervejeiras (Minella, 1999a). Até então a produção brasileira não havia recebido nenhum apoio federal.

A inserção da cultura no bioma Cerrado propiciou um aumento da produção nacional, diminuindo, assim, a dependência do país em relação ao malte 
estrangeiro. A cevada tem sido utilizada como nova opção de cultivo, servindo como alternativa para a rotação com o feijão e a soja, e encontrando na concorrência com o trigo uma boa resposta econômica. A cevada é uma cultura alternativa ao sistema de produção irrigado do Cerrado, mostrando boa adaptação às condições edafoclimáticas deste bioma, baixa incidência de doenças e elevado potencial produtivo (Amabile et al., 2004b). Além disso, o plantio no Cerrado propicia a colheita na ausência de chuvas, o que resulta em sementes limpas, sem a presença de fungos e sem dormência. Segundo Amabile et al. (2002), essas condições, favorecem à indústria malteira, que pode utilizar essas sementes sem haver a necessidade de armazenamento.

Apesar da sensibilidade ao fotoperíodo, a cevada cultivada no Cerrado vem obtendo rendimentos de grãos bem superiores aos provenientes da região Sul, com cerca de $8.500 \mathrm{~kg} \cdot \mathrm{ha}^{-1}$ em campo experimental e $7.200 \mathrm{~kg} \cdot \mathrm{ha}^{-1} \mathrm{em}$ lavoura comercial (Embrapa, 1999). O principal fator que determina esse elevado rendimento de grãos é a correta adubação aliada à época de semeadura, resultando em uma colheita sem incidência de chuvas e um total controle dos aspectos agronômicos como irrigação, fertilizantes e agrotóxicos.

\section{OBjetivo}

O objetivo do trabalho foi avaliar a interação de seis materiais genéticos de cevada cervejeira quanto a fenologia e graus-dia em quatro diferentes doses de nitrogênio em ambiente de Cerrado irrigado.

\section{REVISÃo BIBLIOGRÁFICA}

\subsection{Cerrado}

O Cerrado é o segundo maior bioma do Brasil, ficando atrás apenas da Amazônia. Abrange os estados da Bahia, Ceará, Goiás, Maranhão, Mato Grosso, Mato Grosso do Sul, Minas Gerais, Pará, Rondônia e Tocantins e o Distrito Federal. Também são encontradas áreas de Cerrado nos estados do Piauí, Roraima, Amapá e São Paulo. Em sua totalidade, é responsável por aproximadamente 204 milhões 
de hectares, cerca de $24 \%$ do território nacional. Atualmente restam apenas 61,2\% do território original cobertos com Cerrado, sua grande maioria na região Meio-Norte (Eiten, 1993; Ribeiro \& Walter, 1998; Embrapa, 2007). Possui também cerca 30\% da biodiversidade nacional e $5 \%$ da flora e fauna mundiais, caracterizando-o como a savana mais diversa do mundo (IBAMA, 2000).

Há 20 anos, o enorme potencial agrícola do Cerrado já era discutido, destacando-se a necessidade de uma agricultura de grandes investimentos tanto na própria terra como em pesquisas (Goedert, 1985).

O clima do bioma é bastante característico, tendo dois períodos marcantes: um chuvoso durante o verão, com precipitações médias entre 1200 a $1800 \mathrm{~mm}$ e duração de aproximadamente 6 meses, e outro seco no inverno, com inicio em maio e término em setembro (Adámoli et al., 1986). Durante a estação chuvosa podem ocorrer curtos períodos secos, denominados veranicos, responsáveis por grandes prejuízos na agricultura da região (Assad, 1994). As temperaturas médias do ar variam entre $22^{\circ} \mathrm{C}$ a $27^{\circ} \mathrm{C}$. Segundo a classificação de Köpen, o clima da região é do tipo Aw (tropical úmido de savana, com inverno seco e verão chuvoso), apesar de ocorrem os tipos climáticos Cwa (tropical de altitude, com semestre de inverno seco e verões quentes) e Cwb (tropical de altitude, com semestre de inverno seco e verões brandos) nas regiões de altitude mais elevadas.

Os solos do Cerrado são predominantemente das classes latossolosvermelhos e latossolos vermelho-amarelos, com cerca de $46 \%$ de toda a extensão do bioma (Reatto et al., 1998; Correia et al., 2004). Além das classes acima citadas, ainda podem ser encontrados Neossolos Quartzarênicos (Areia Quartzosa), Cambissolos, Neossolos Flúvicos (Aluviais) e Hidromórficos (Resende et. al., 2002).

As principais características dos latossolos do Cerrado são matéria orgânica baixa, variando entre 3,0 a 5,0\%, presença de óxidos e ferro e alumínio, altamente intemperizados, baixa capacidade de troca catiônica (CTC), pH baixo e carência de nutrientes, principalmente fósforo (Lopes, 1983; Malavolta \& Kliemann, 1985; Resende et al. 2002). Portanto, plantio tecnificado e altamente produtivo na região é feito somente com o uso de corretivos e adubação química.

Sob sistema irrigado, o Cerrado vem apresentado bons resultados durante a época seca, totalizando uma área de 478632 hectares $(0,23 \%$ da área total do bioma) irrigada por 6001 pivôs-centrais (Lima et al., 2007). As necessidades edafoclimáticas da cultura da cevada são beneficiadas pelas características da 
região, tendo demonstrado, portanto, bastante adaptabilidade no Cerrado sob cultivo irrigado no inverno (Fagundes, 2003). O cultivo de cevada favorece uma rotação de culturas com as demais, ajudando na quebra do ciclo de várias pragas e doenças observadas com a monocultura intensiva.

\subsection{Cevada}

A cevada (Hordeum vulgare L.) é uma gramínea pertencente à família das Poaceae (antiga Gramineae), tribo Triticeae e ao gênero Hordeum, constituída por duas subespécies: Hordeum vulgare e Hordeum spontaneum. Tem distribuição ampla, ocorrendo em grande parte das regiões temperadas do mundo. A espécie Hordeum spontaneum é reconhecida como a ancestral imediata de todas as cevadas cultivadas. (Minella, 2001). O gênero Hordeum é composto por 32 espécies, incluindo diplóides, tetraplóides e hexaplóides, com 7 cromossomas básicos. (Bothmer et al., 1991)

Estas espécies incluem formas perenes, anuais, autógamas e alógamas que se encontram principalmente nas áreas temperadas, estendendo-se às regiões árticas e subárticas na Sibéria, no Alasca e na Patagônia (Bothmer, 1995, citado por Minella, 1999b). Algumas espécies ocorrem próximas nas zonas subtropicais da América do Sul, no Sudoeste brasileiro e Nordeste argentino. O maior número de espécies é encontrado no sudeste asiático e no sul da América do Sul (Minella, 1999b).

A Hordeum vulgare L., dipóide, com 14 cromossomos (2n=14), hermafrodita, autógama, é a única espécie cultivada do gênero. Ainda há duas subespécies, a Hordeum vulgare ssp. vulgare e a Hordeum vulgare ssp. spontaneum. A Hordeum vulgare ssp. vulgare L. engloba todas as variedades férteis, enquanto a Hordeum vulgare ssp. spontaneum L. é constituída pelas cevadas selvagens inférteis com as da ssp. vulgare.

Dentro das espécies cultivadas, ainda pode-se distinguir dois tipos principais: as que contêm duas fileiras (covariedade distichum) e as de seis fileiras (vulgare) de grãos. Essas formas resultaram de mutações na fertilidade das espiguetas laterais (Bothmer \& Jacobsen, 1985; citados por Minella, 1999b).

Restos arqueológicos de grãos encontrados na região do Crescente Fértil ("Fertile Crescent"), localizado no Oriente Médio, atualmente constituído pelos 
países Israel, Iraque, Turquia, Síria e Jordânia, indicam que a cultura foi domesticada a cerca de 8000 a.C. (Zohary \& Hopf 1993; Diamond 1998). A primeira descrita foi a cevada dística. Apenas por volta de 6000 a.C. surgem relatos da cevada de seis fileiras de grãos e da cevada nua (cujo grão não é aderido a pálea e a lema) (Smith, 1995).

Existem dois centros de origem da cevada, de acordo com Vavilov (1951), citado por Poehlman (1959). Um compreendendo a Etiópia e o norte da África, com cevadas de aristas compridas. O outro na China, Japão e Tibet com aristas curtas ou sem aristas.

Smith (1995) evidencia a rápida evolução da cevada quando comparada a outras culturas, em que uma cevada selvagem (Hordeum spontaneum) originou a cevada cultivada atualmente (Hordeum vulgare L.). Smith também observou que apenas algumas características diferenciam as duas espécies de cevada acima citadas, entre elas maior resistência ao quebramento da raquis, produção de apenas uma espiga por planta e espiga com seis fileiras férteis. Ambas são diplóides $(2 n=14$ cromossomos), autógamas, cleistogâmicas e hermafroditas (Minella, 2005).

A cevada pode ser cultivada tanto no inverno como na primavera, semelhante ao trigo. Baixas temperaturas (até $10{ }^{\circ} \mathrm{C}$ ) são necessárias durante o período de reprodução para as cevadas de inverno, podendo influenciar na produtividade quando não ocorrem (Smith, 1995).

A morfologia interna da cevada é descrita como sendo composta de uma espiga terminal, com três espiguetas ligadas alternadamente em nós da ráquis. $\mathrm{Na}$ cevada dística apenas as espiguetas laterais são estéreis, sendo apenas a central fértil e formadora de semente, já na cevada hexástica as três espiguetas são férteis e, portanto, originam semente (Starling, 1980; Smith, 1995). Cada espigueta é constituída por duas glumas e uma flor completa com três estames e o pistilo encobertos pela pálea e a lema (glumelas). O término da lema pode ser em arista ou em capuz. Na cevada nua a pálea e a lema não são aderidas ao grão.

A cevada é uma planta cleistogâmica, portanto autógama, com deiscência das anteras, o que normalmente ocorre antes da abertura da flor e, frequentemente, da emergência da espiga. A fecundação cruzada ou alogamia existe, apesar da existência de cleistogâmia, e pode chegar a 1\%. Essa taxa de alogamia pode ser favorecida quando a planta é exposta a temperaturas mais amenas, umidade adequada e muita luminosidade (Minella, 2005). 
A morfologia da folha pode ser descrita pela existência de uma bainha que inclui o pecíolo, a lígula, aurícula, colar e folha bandeira. A lígula é fina e não possui uma função definida, no entanto é encontrada na maioria das cultivares de cevada e de trigo. A aurícula consiste de duas pinças acessórias que abraçam o pecíolo. $\mathrm{Na}$ cevada as aurícolas são bem proeminentes ao contrário das encontradas no trigo (Smith, 1995).

\subsection{SituAÇão MUNDIAL E BRASILEIRA}

A cevada é o quarto cereal mais semeado no mundo, ficando atrás apenas de trigo, arroz e milho (FAOSTAT, 2008). Os grãos são utilizados principalmente em alimentação animal (7\%) e produção de malte (86\%) (Minella et al., 2007). Sua demanda no mercado nacional é crescente e a produção, concentrada principalmente nos estados tradicionais do Sul do país, está longe de atender as necessidades industriais. $O$ déficit gerado no mercado interno pelo cereal é suprido com importações que oneram a balança comercial do país. Resultados recentes de pesquisa indicam que o Cerrado tem potencial para suprir esta demanda por grãos de cevada, dando oportunidade e oferta ao negócio agrícola, de forma a incluir novas ofertas comerciais (Amabile et al., 2007).

Segundo a Food And Agriculture Organization Of The United Nations - FAO, a produção mundial de cevada no ano de 2006 foi de aproximadamente 138,7 milhões de toneladas, colhidas em uma área de 55,5 milhões hectares, reportando uma produtividade mundial média de aproximadamente $2.500 \mathrm{~kg} \cdot \mathrm{ha}^{-1}$. Os maiores produtores mundiais são:

$\left.1^{\circ}\right)$ Rússia, com cerca de 18,1 milhões de toneladas colhidas em 9,5 milhões de hectares;

$2^{\circ}$ ) Canadá, com 10,0 milhões de toneladas em 3,3 milhões de hectares;

$\left.3^{\circ}\right)$ Alemanha, com 12,0 milhões de toneladas em 2,0 milhões de hectares;

$\left.4^{\circ}\right)$ França, com 10,4 milhões de toneladas em 1,6 milhões de hectares (FAOSTAT, 2008).

A Argentina é o maior produtor na América Latina, com 1,26 milhões de toneladas colhidas em 337 mil hectares, seguida pelo México, com 874 mil toneladas colhidas em 317 mil hectares (FAOSTAT, 2008). 
Atualmente o Brasil é o terceiro em produção do cereal na América Latina. Minella et al. (2007) reportaram a área colhida e produção obtida no país, sendo de 90 mil hectares e 250 mil toneladas, respectivamente. Os autores também destacaram a produtividade média brasileira, ficando por volta de $2.761 \mathrm{~kg}^{\mathrm{ha}} \mathrm{ha}^{-1}$, valor acima da média mundial.

O rendimento médio obtido em 2004 no estado de Goiás foi de $4.227 \mathrm{~kg} \mathrm{ha}^{-1}$, sendo aproximadamente 35\% maior do que a média do Paraná e 37,5\% maior que o do Rio Grande do Sul (Minella et al., 2005). No ano de 2005 a produtividade média registrada no estado de Goiás (3.979 kg.ha-1) também foi superior a do Rio Grande do Sul (2.272 kg.ha-1) e Paraná (2.209 kg.ha-1) (MAPA, 2008).

\subsection{NitROGÊNIO}

A adubação nitrogenada é uma prática bastante utilizada quando o solo possui restrita capacidade em fornecer a quantidade de nitrogênio $(N)$ exigida pela cultura ao longo do seu desenvolvimento (Wamser \& Mundstock, 2007). O nitrogênio é o nutriente mais demandado pelas plantas, principalmente gramíneas. A deficiência desse mineral é bastante evidente no Cerrado, uma vez que uma adubação correta aumenta significativamente os índices de produtividade nas culturas (Freitas, et al., 1963; Britto et al., 1971; Freitas et al., 1971; Grove et al., 1980).

A eficiência agronômica da adubação nitrogenada depende de fatores ambientais, tais como condições edáficas e meteorológicas da planta, do estádio de desenvolvimento em que ocorre a aplicação do fertilizante, e também das características da planta, como a taxa de absorção, a eficiência de utilização do nutriente e genótipo (Matsushima, 1970; Wamser \& Mundstock, 2007).

Cerca de $98 \%$ do nitrogênio é encontrado complexado em formas orgânicas, a qual se torna indisponível para as plantas, enquanto em forma mineral encontra-se em íons $\mathrm{NH}_{4}{ }^{+}$e $\mathrm{NO}_{3}{ }^{-}$(Stevenson, 1969, citado por Malavolta, 2006).

Alguns parâmetros intrínsecos do solo, como acidez, aeração, umidade, temperatura e mineralogia, são fundamentais para que haja as transformações do nitrogênio orgânico em inorgânico. As perdas desse nutriente, somada com as deficiências encontradas nos solos, fazem com que este seja um dos fatores mais limitantes na produção da maioria das culturas (Camargo,1996). 
As perdas de $\mathrm{N}$ no Cerrado ocorrem principalmente por volatilização, no período da seca. Na estação chuvosa, o nutriente é perdido principalmente por lixiviação, ocorrendo também emissões gasosas, nas formas de óxido nítrico e nitroso (Carvalho, 2005). Em solos tropicais, as perdas ocorrem por causa da rápida mineralização, de $40 \%$ a $60 \%$ em quatro semanas pós-incorporação (Quintana, 1987).

Devido a sua grande mobilidade, esse nutriente deve ser aplicado de forma parcelada, visando assim diminuir as perdas (Suhet et al., 1988). Delouche (1981) ainda complementa que para obter sementes de melhores qualidades essa adubação deve ser feita de modo adequado, atendendo as necessidades da planta em diversas fases de seu crescimento. Wamser \& Mundstock (2007) evidenciaram que a melhor resposta à suplementação nitrogenada em cevada ocorre entre a emissão da $3^{\mathrm{a}}$ e $9^{\mathrm{a}}$ folha do colmo principal.

A quantidade de nutriente oferecido influencia diretamente a qualidade fisiológica das sementes (Araújo et al., 1994). Ratttunde \& Frey (1986) observaram que o nitrogênio está diretamente ligado ao acréscimo de proteína nas sementes. Em se tratando de cevada cervejeira, onde o valor máximo de proteína aceitável é de 12\% (Brasil, 1996), a quantidade de nitrogênio deve ser dosada e aplicada na época estipulada, para que não ultrapasse o teor de proteína desejado no grão (Guerra, 1994; Guerra, 1995).

A instabilidade do teor de proteína dos grãos apontada por Silva \& Andrade (1985) e Guerra et al. (1987) ocorre devido à quantidade de nitrogênio aplicada e pelas condições de estresse de água no solo, o que promove grandes oscilações, desde valores muito baixos, em torno de $7 \%$ a $8 \%$, até valores extremos acima de $12 \%$.

Peruzzo $(1988 ; 2001)$ afirmou que o aumento na dose de $\mathrm{N}$ acarretou em um maior rendimento, porém causou uma redução na quantidade de grãos de primeira classe e, consequentemente, uma diminuição do peso de mil sementes de cevada. A dose máxima de nitrogênio aplicada na cultura é de $60 \mathrm{~kg} \mathrm{ha}^{-1}$. Doses maiores proporcionarão teores elevados de proteína, o que não é recomendado para fins cervejeiros (Amabile et al., 2004c). Fontoura et al. (2001), Fontoura \& Moraes (2003), Poletto et al. (2003) e Teixeira et al. (2003) também verificaram o aumento da produtividade com maiores doses do nutriente. 


\subsection{FEnOLOGiA}

Para Lieth (1974), citado por Mantovani \& Martins (1988), a fenologia pode ser definida como "o estudo da ocorrência de eventos biológicos repetitivos, das causas de sua ocorrência em relação a fatos biótipos e abióticos e as inter-relações entre as fases por esses eventos da mesma ou de diferentes espécies". De forma mais simplificada, entende-se a fenologia como o estudo das manifestações fisionômicas das plantas, desde a emergência até sua morte (Fournier, 1976; Cestaro, 1984; Costa et al., 1988).

O entendimento da fenologia das plantas auxilia na compreensão dos períodos de crescimento e reprodução das plantas (Talora \& Morellato, 2000). crescimento e o desenvolvimento da planta, desde a semente até a maturidade, passam por estádios fenológicos definidos morfologicamente, sendo estes fortemente influenciados pelo meio ambiente (Saarikko \& Carter, 1995).

O rendimento de grãos, em cereais de estação fria, é composto pelo número de espigas $x$ área $^{-1}$, número de grãos $x$ espiga $^{-1}$ e massa de grão. Ao longo da ontogênese da cultura, o início da formação e a concretização do potencial destas estruturas, ou seja, a quantidade final de cada componente do rendimento, ocorrem em diferentes estádios fenológicos (McMaster, 1997).

\subsection{Escala Zadoks, Chang e KonzaK}

As etapas (estádios) de crescimento e desenvolvimento das plantas dos cereais estendem-se da germinação até a maturação de colheita. Elas foram descritas em escalas, sendo as mais conhecidas: $1^{\underline{a}}$ ) escala de Feekes, datada de 1941 e ilustrada e ampliada por Large (1954); $2^{\text {a }}$ ) escala Zadoks, Chang e Konzak (1974); e 3르) escala de Haun (1973).

A escala de Zadoks et al. (1974) subdivide com mais detalhes os estádios secundários de desenvolvimento, especialmente da germinação e pós-antese. Esta escala utiliza um código decimal. O ciclo da planta é divido em nove etapas e cada uma destas, subdividida em nove outras etapas.

Essa escala foi reconhecida pelo meio acadêmico como sendo a melhor escala para estádios de crescimento de cereais disponível. Diferentemente da escala de Feekes, que foi designada apenas para cereais de grãos pequenos na 
região do nordeste europeu, a escala Zadoks pode ser utilizada para todos os cereais em todo o mundo.

Anderson et al. (2002) utilizou a escala Zadoks para desenvolver um guia de crescimento e desenvolvimento para a cevada. Segundo o autor, a cultura se distingue de outros cereais por apresentar significativas diferenças no tipo da espiga e nos hábitos de crescimento, tanto em cevada dística quanto hexástica.

\subsection{GraUS-DIA}

A velocidade das reações químicas e os processos internos de transporte são as variáveis responsáveis pelo crescimento e desenvolvimento vegetal e são fortemente influenciadas pela temperatura do ar e, a melhor forma de relacioná-la ao desenvolvimento é utilizando o sistema de unidades térmicas ou graus-dia (Brunini et al., 1976; Pereira et al., 2002).

Segundo Cao \& Moss (1991) e Ball et al. (1995), o aparecimento de folhas no colmo principal está intimamente relacionado com o acúmulo de unidades térmicas da semeadura ou da emergência na cevada e no trigo.

Reaumur foi considerado o precursor do conceito graus-dia, pois foi quem realizou um dos primeiros estudos relacionando clima e plantas, por volta de 1735, na França (Pereira et al., 2002). Ele adotou que o somatório térmico é a quantidade de energia que uma planta necessita para assumir determinado grau de maturidade. Além disso, Reaumur, citado por Souza (1989) concluiu que a soma da temperatura do ar desde a germinação até a maturação da planta será a mesma, independente do local, e que a planta só irá finalizar o ciclo se for atingido o soma de temperatura determinada.

Ometto (1981) e Souza (1990) definiram graus-dia ou soma térmica como sendo um acúmulo diário de energia que fica acima da condição mínima e abaixo da máxima exigida pela planta. Ou seja, o aumento da temperatura do ar acelera o desenvolvimento da planta, reduzindo o seu ciclo e vice-versa (Infeld \& Silva,1987). Baseado nisso, explica-se por que uma mesma cultura possui diferentes durações de ciclo quando cultivadas em localidades de diferentes temperaturas.

O conceito de graus-dia assume a ocorrência de temperaturas basais (inferior, Tb; e superior, TB). Se a temperatura média for maior que TB e menor que Tb a planta não se desenvolverá ou o fará lentamente. Cada espécie ou mesmo 
variedade possui suas temperaturas basais, que pode ainda variar de acordo com 0 estádio fenológico que a planta se encontra (Pereira et al., 2002). Entretanto, Camargo et al. (1987) relataram que é comum adotar apenas uma temperatura base para todo o ciclo da planta.

Estudos realizados por Kirby et al. (1982) na Ucrânia indicaram que a temperatura base para o desenvolvimento da cevada pode variar de $0{ }^{\circ} \mathrm{C}$ para 4,3 ${ }^{\circ} \mathrm{C}$, dependendo da data de semeadura. Na Noruega, Strand (1987) descreveu que 0 ${ }^{\circ} \mathrm{C}$ foi uma temperatura base apropriada para prever o desenvolvimento e maturação do cereal. Gear (2005), estudando a resposta de cultivares de cevada cervejeira ao fotoperíodo concluiu que a temperatura média, sobre a taxa de desenvolvimento, indicou uma temperatura base de $0^{\circ} \mathrm{C}$ em coincidência com outros autores (Kernich et al., 1995).

De acordo com o folder técnico da cultivar de cevada BRS 180, recomendada para o bioma Cerrado, foram necessários 1600 graus-dia até a maturação fisiológica (Embrapa, 1999).

Segundo Warrington \& Kanemasu (1983), os métodos de graus-dia foram desenvolvidos com a finalidade de se fazer uma previsão dos estádios fenológicos, identificação de melhores épocas de semeadura, escalonamento da produção e programação do melhoramento genético. Paralelamente a isso, esses parâmetros também podem ser utilizados para se determinar as épocas mais adequadas de se fazer os tratos culturais, como aplicação de fertilizantes, agrotóxicos e execução da colheita (Ometto, 1981).

O conhecimento da constante térmica e da temperatura base são informações que possibilitam um melhor planejamento da semeadura, colheita, escolha de variedades e acompanhamento em tempo real do desenvolvimento da cultura (Pereira et al., 2002).

\subsection{TEMPERATURA DO AR}

A cevada tolera temperaturas do ar acima de $32 \stackrel{\circ}{ }$, desde que em clima seco, o mesmo não ocorre se a umidade do ar estiver elevada (Chapman \& Carter, 1976). Para a cevada, altas temperaturas do ar e muita chuva caracterizam baixa produtividade de grãos (Baldanzi et al., 1988). 
Brocklehurst (1977), trabalhando com trigo, identificou que a taxa de enchimento do grão é dependente do número de células formadas no grão em desenvolvimento durante as primeiras duas semanas após a antese. Essa taxa é aumentada moderadamente com a elevação da temperatura, enquanto a duração do enchimento é significativamente reduzida (Wych et al., 1982; Van Sanford, 1985). O aumento na taxa, no entanto, não é suficiente para compensar a perda no peso do grão em conseqüência da redução no número de dias de enchimento (Caley et al., 1990).

De acordo com Chapman \& Carter (1976), em ambientes secos e quentes, os grãos de cevada acusam elevados teores de proteína. Em condições de umidade do ar ideal, o fertilizante nitrogenado é utilizado pela planta para aumentar a produção sem causar acréscimo no teor de proteína do grão. Se as condições climáticas na pós-floração estiverem ruins pode haver um excessivo aumento no teor de proteína do grão.

Marcos Filho (2005) evidenciou que as temperaturas do ar mais altas favoreceram o aumento do teor de proteína no trigo. A temperatura do ar ótima para a síntese de proteína na cultura do trigo está limitada a uma estreita amplitude, pois todos os processos que estão relacionados com esta síntese são dependentes dessa temperatura e cada processo trabalha em coeficientes diferentes (Larcher, 2000). Em seu trabalho, Larcher mostra que o trigo condicionado a maiores temperaturas do ar, obteve uma síntese mais elevada de proteína. De acordo com Bayma (1960), a variação da proteína do trigo depende muito mais do clima e provavelmente do solo, do que da cultivar em si.

\section{MATERIAL e MÉtodos}

\subsection{LOCALIZAÇÃO dO ENSAIO}

O experimento foi conduzido no campo experimental da Embrapa Cerrados, Planaltina-DF, situado a 15ำ35'30" latitude S, 47ํ42'30" longitude $\mathrm{O}$ e altitude de $1.007 \mathrm{~m}$, entre 9 de junho de 2005 e 23 de setembro de 2005.

O solo do ensaio foi classificado como LATOSSOLO VERMELHO Distrófico típico, argiloso, cuja análise na profundidade de 0 a $10 \mathrm{~cm}$ resultou em: 0,0 
mmol $\mathrm{c}_{\mathrm{Cm}} \mathrm{dm}^{-3}$ de Al; 31,6 mmol $\mathrm{c} \cdot \mathrm{dm}^{-3}$ de Ca; $9,9 \mathrm{mmol}_{\mathrm{c}} \cdot \mathrm{dm}^{-3}$ de Mg; 37,67 mg.kg ${ }^{-1}$ de $\mathrm{P} ; 2,6 \mathrm{mmol}_{\mathrm{c}} \cdot \mathrm{dm}^{-3}$ de $\mathrm{K} ; 25,6 \mathrm{~g} \cdot \mathrm{kg}^{-1}$ de $\mathrm{M} . \mathrm{O}$ e pH (água) de 6,27. Na camada de 10 a 20 $\mathrm{cm}$ os resultados encontrados foram: $0,0 \mathrm{mmol}_{\mathrm{c}} \cdot \mathrm{dm}^{-3}$ de Al; $30,5 \mathrm{mmol}_{\mathrm{c}} \cdot \mathrm{dm}^{-3}$ de $\mathrm{Ca}$; 9,3 mmol $\mathrm{c} \cdot \mathrm{dm}^{-3}$ de Mg; 30,87 mg.kg ${ }^{-1}$ de P; $1,6 \mathrm{mmol}_{\mathrm{c}} \cdot \mathrm{dm}^{-3}$ de K; $23,2 \mathrm{~g} \cdot \mathrm{kg}^{-1}$ de M.O e $\mathrm{pH}_{\text {(água) }}$ de 6,35.

Seguindo a classificação de Köoppen para aspectos climáticos, á área está inserida no domínio morfoclimático do Cerrado, com clima tropical estacional (Aw), ou seja, com inverno seco e chuvas máximas de verão. Apresenta uma precipitação média anual entre $1.400 \mathrm{~mm}$ e $1.600 \mathrm{~mm}$ e temperatura média anual entre $22{ }^{\circ} \mathrm{C}$ e $27 \stackrel{\circ}{\circ}$ (Adámoli et al. 1986; Nimer, 1989).

\subsection{Características do ensaio}

Foi utilizado o delineamento experimental de blocos ao acaso em parcelas subdivididas, com três repetições, onde as parcelas receberam as doses de nitrogênio e as subparcelas os materiais genéticos. As parcelas eram compostas por 10 linhas de 4 metros de comprimento, espaçadas $20 \mathrm{~cm}$ entre si, com a área útil de $8 \mathrm{~m}^{2}$. Os genótipos que compuseram este ensaio foram o AF 9585, CEV 98074, as variedades $L A C E Y$ e Prestige, americana e francesa, respectivamente, além das cultivares nacionais BRS 180 e BRS 195.

Foram utilizados quatro níveis de nitrogênio: $0,20,40$ e $80 \mathrm{~kg}^{\mathrm{h}} \mathrm{ha}^{-1}$,na forma de uréia. $A$ adubação de base foi de $20 \mathrm{~kg} \mathrm{ha}^{-1}$ de $\mathrm{N}$, exceto para a parcela de $0 \mathrm{~N}$, que não recebeu nenhum tipo de adubação nitrogenada. A parcela $20 \mathrm{~N}$ recebeu adubação nitrogenada apenas em base, enquanto as parcelas 40 e $80 \mathrm{~N}$ receberam $20 \mathrm{~kg} \cdot \mathrm{ha}^{-1}$ de $\mathrm{N}$ na base e duas coberturas nitrogenadas de 10 e $30 \mathrm{~kg}^{\mathrm{h}} \mathrm{ha}^{-1}$ cada uma, respectivamente, nos dias 06/07 e 22/07, de N na forma de uréia. A adubação foi feita por meio de fertirrigação com um sistema de aspersão com padrão de molhamento circular. Aplicou-se, para completar a adubação de semeadura, 100 kg.ha- ${ }^{-1}$ de $\mathrm{K}_{2} \mathrm{O}$ somada com $117 \mathrm{~kg}$ ha ${ }^{-1}$ de $\mathrm{P}_{2} \mathrm{O}_{5}$ baseada nos resultados das análises de solo, em todas as parcelas.

As irrigações, por aspersão, foram efetuadas quando a umidade volumétrica medida por sonda Delta-T, instalada na linha de plantio a uma profundidade de 15 $\mathrm{cm}$, atingia valor preestabelecido de $0,26 \%$, que corresponde a um consumo de $50 \%$ da água disponível no perfil do solo, e, em seguida, calculou-se a lamina d'água a 
ser aplicada para repor a umidade até a capacidade de campo. Essas medidas foram tomadas a partir de 8 horas da manhã, durante todo o ciclo da cultura.

Para o controle de ervas daninhas foram realizadas capinas manuais. Foi feita uma aplicação de inseticida clorpirifós $480 \mathrm{~g} \cdot \mathrm{L}^{-1}$ para o controle da lagarta rosca (Agrotis ipsilon).

\subsection{OBTENÇÃO dE dADOS}

\subsubsection{VARIÁVEIS CLIMÁTICAS}

\section{TemperatURA do AR}

Os dados horários da temperatura do ar, entre os dias 16/06/2005 e 26/08/2005, foram coletadas em uma estação climatológica Campbel localizada próxima a área de estudo.

A temperatura média diária do ar foi calculada de acordo com a média aritmética das temperaturas médias horárias, segundo a equação:

$$
\begin{gathered}
T m=\left(T_{1 h}+T_{2 h}+T_{3 h}+\ldots+T_{24 h}\right) / 24 \text {, onde: } \\
\mathrm{T}_{1 \mathrm{~h}-24 \mathrm{~h}}: \text { temperatura média do } \mathrm{ar}, \mathrm{em} \stackrel{\circ}{\circ} \mathrm{C} \text {, a cada hora. }
\end{gathered}
$$

\section{Graus-DIA}

Durante o ciclo da cultura, avaliou-se os estádios fenológicos de emergência, primeiro nó, emborrachamento, emergência da folha bandeira, floração e espigamento. Para cada estádio foram calculados os graus-dia, a partir da emergência das plantas, segundo a equação (Pereira et al., 2002):

$$
G D_{i}=\sum\left(T m_{i}-T b\right), \text { onde: }
$$

Tm: temperatura média do ar, em ${ }^{\circ} \mathrm{C}$, no dia $i$;

$\mathrm{Tb}$ : temperatura basal, em ${ }^{\circ} \mathrm{C}$, da cevada. 
A temperatura basal utilizada foi de $0{ }^{\circ} \mathrm{C}$, seguindo os dados de Gear (2005) e Savin et al. (1997).

\subsection{FASES FENOLÓGICAS}

As avaliações foram realizadas visualmente em intervalos de 3 a 8 dias, entre a emergência e o espigamento. Os valores das fases fenológicas foram atribuídos de acordo com o proposto por Zadoks et al. (1974).

\section{Resultados e Discussão}

\subsection{Escala ZaDOKS}

As tabelas de 1 a 4 apresentam o número de graus-dia que cada genótipo levou em seu ciclo, da emergência ao espigamento, tomando como ponto de partida o plantio, nas quatro diferentes doses. As fases fenológicas analisadas foram emergência da planta, surgimento do primeiro nó, emborrachamento do colmo, aparecimento da folha bandeira, floração e espigamento, correspondendo, de acordo com a escala Zadoks, aos números 10, 31, 36, 39, 51 e 69 (Zadoks et al., 1974). Entretanto, como a escala Zadoks foi determinada para o trigo, há necessidade de um ajuste, sendo, portanto, os números referentes aproximados. A emergência ocorreu 7 dias após o plantio em todas as cultivares testadas.

A cultivar BRS 195 mostrou-se a mais tardia em relação às outras linhagens testadas em todas as doses, reportando sempre o maior somatório calórico em todas as fases fenológicas estudadas.

A variedade Prestige foi, após a BRS 195, a que apresentou maior valor em graus-dia para todas as fases e em todas as doses.

As demais (AF 9585, CEV 98074 e BRS 180) foram intermediárias para todas as doses quando comparadas à BRS 195 e LACEY. Entretanto, a floração nas doses $0 \mathrm{~N}$ e $20 \mathrm{~N}$ do material genético CEV 98074 apresentaram somatório calórico abaixo da encontrada para a variedade LACEY.

Com exceção da formação do 1ํ nó, a variedade LACEY mostrou-se a mais precoce quanto ao emborrachamento, folha bandeira, floração e espigamento, em 
todas as doses estudadas. No surgimento do $1^{\circ}$ nó, com exceção da dose $0 \mathrm{~N}$, em que os genótipos AF 9585, CEV 98074 e BRS 180 reportaram somatório calórico de 703,1 graus-dia, sendo as mais precoces, nas outras doses a variedade LACEY foi a mais precoce.

Através do estudo dos estádios fenológicos pode-se realizar um manejo diferenciado dos tratos culturais, como a lâmina de água a ser aplicada, o turno de rega e o momento adequado de realizar adubação nitrogenada, uma vez que os estádios fenológicos se diferenciam em função do material genético apregoado (Anghinoni, 1986; Mundstock, 1999; Wamser \& Mundstock, 2007). Nota-se, por exemplo, que a floração para a variedade LACEY, na dose $40 \mathrm{~N}$, foi de $1.012,6$ graus-dia, enquanto a cultivar BRS 195 necessitou de 1.456,1 graus-dia, o que resulta em uma diferença de 443,5 graus-dia. Utilizando a temperatura média do ar quando do florescimento, que foi de $19,9 \stackrel{\circ}{\circ}$, têm-se em média uma diferença de 22 dias entre o mesmo evento nas cultivares analisadas.

Quanto ao número de folhas, no momento do surgimento do primeiro nó (figuras 7 a 12, em anexo), apenas a cultivar BRS 195 manteve-se com 5 folhas em todas as doses analisadas, sendo que para a dose $40 \mathrm{~N}$ o material genético demonstrou menor número que nas outras doses (2 folhas) quando da primeira medição. Entre as doses $0 \mathrm{~N}$ e $20 \mathrm{~N}$, os genótipos CEV 98074 e Prestige responderam de forma parecida, mantendo o mesmo número final de folhas. Já para LACEY e BRS 180, nas mesmas doses, o comportamento foi outro, reportando uma redução no número final de folhas no $1^{\circ}$ nó (de 4 para 3). Nas doses $20 \mathrm{~N}$ e $40 \mathrm{~N}$, os genótipos AF 9585, LACEY e Prestige mantiveram o mesmo número de folhas (4, 3 e 4, respectivamente). Entre os tratamentos $40 \mathrm{~N}$ e $80 \mathrm{~N}$, observou-se que o número de folhas quando do surgimento do primeiro nó continuou o mesmo nos materiais genéticos LACEY e BRS 180 (3 e 4 folhas, respectivamente), e aumentou para a CEV 98074 e Prestige (de 3 para 4 folhas e de 4 para 5 folhas, respectivamente). 
Tabela 1. Graus-dia, em ${ }^{\circ} \mathrm{C}$, do $1^{\circ}$ nó ao espigamento dos seis genótipos na dose $0 \mathrm{~N}$.

\begin{tabular}{l|c|c|c|c|c}
\hline \multirow{2}{*}{ Genótipos } & \multicolumn{5}{|c}{ Fases fenológicas } \\
\cline { 2 - 6 } & $\mathbf{1}$ Nó & Emborrachamento & Folha Bandeira & Floração & Espigamento \\
\hline AF 9585 & 703,1 & 947,8 & 991,0 & $1.075,1$ & $1.195,5$ \\
\hline CEV 98074 & 703,1 & 906,3 & 947,8 & $1.033,1$ & $1.195,5$ \\
\hline LACEY & 721,3 & 843,4 & 906,3 & $1.054,9$ & $1.135,0$ \\
\hline Prestige & 926,7 & $1.012,6$ & $1.175,1$ & $1.237,5$ & $1.389,6$ \\
\hline BRS 180 & 703,1 & 947,8 & 991,0 & $1.195,5$ & $1.258,3$ \\
\hline BRS 195 & $1.094,8$ & $1.215,5$ & $1.258,3$ & $1.389,6$ & $1.539,9$ \\
\hline
\end{tabular}

Tabela 2. Graus-dia, em ${ }^{\circ} \mathrm{C}$, do $1^{\circ}$ nó até o espigamento dos seis genótipos na dose $20 \mathrm{~N}$.

\begin{tabular}{l|c|c|c|c|c}
\hline \multirow{2}{*}{ Genótipos } & \multicolumn{5}{|c}{ Fases fenológicas } \\
\cline { 2 - 6 } & $\mathbf{1}$ Nó & Emborrachamento & Folha Bandeira & Floração & Espigamento \\
\hline AF 9585 & 665,8 & 926,7 & 991,0 & $1.075,1$ & $1.175,1$ \\
\hline CEV 98074 & 703,1 & 843,4 & 885,8 & 969,6 & $1.154,6$ \\
\hline LACEY & 615,2 & 843,4 & 906,3 & $1.033,1$ & $1.114,9$ \\
\hline Prestige & 885,8 & $1.012,6$ & $1.135,0$ & $1.258,3$ & $1.389,6$ \\
\hline BRS 180 & 665,8 & 885,8 & $1.012,6$ & $1.094,8$ & $1.175,1$ \\
\hline BRS 195 & $1.012,6$ & $1.154,6$ & $1.237,5$ & $1.366,9$ & $1.518,1$ \\
\hline
\end{tabular}

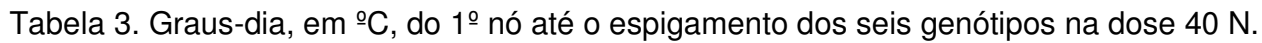

\begin{tabular}{l|c|c|c|c|c}
\hline \multirow{2}{*}{ Genótipos } & \multicolumn{5}{|c}{ Fases fenológicas } \\
\cline { 2 - 6 } & $\mathbf{1}$ Nó & Emborrachamento & Folha Bandeira & Floração & Espigamento \\
\hline AF 9585 & 721,3 & 991,0 & $1.114,9$ & $1.195,5$ & $1.301,4$ \\
\hline CEV 98074 & 703,1 & 969,6 & $1.012,6$ & $1.054,9$ & $1.215,5$ \\
\hline LACEY & 648,4 & 864,5 & 926,7 & $1.012,6$ & $1.114,9$ \\
\hline Prestige & 991,0 & $1.075,1$ & $1.135,0$ & $1.322,4$ & $1.389,6$ \\
\hline BRS 180 & 779,6 & 991,0 & $1.054,9$ & $1.175,1$ & $1.301,4$ \\
\hline BRS 195 & $1.094,8$ & $1.215,5$ & $1.279,8$ & $1.456,1$ & $1.608,4$ \\
\hline
\end{tabular}

Tabela 4. Graus-dia, em ${ }^{\circ} \mathrm{C}$, do $1^{\circ}$ nó até o espigamento dos seis genótipos na dose $80 \mathrm{~N}$.

\begin{tabular}{l|c|c|c|c|c}
\hline \multirow{2}{*}{ Genótipos } & \multicolumn{5}{|c}{ Fases fenológicas } \\
\cline { 2 - 6 } & $\mathbf{1 0}$ Nó & Emborrachamento & Folha Bandeira & Floração & Espigamento \\
\hline AF 9585 & 721,3 & 926,7 & 991,0 & $1.075,1$ & $1.195,5$ \\
\hline CEV 98074 & 703,1 & 969,6 & $1.012,6$ & $1.054,9$ & $1.195,5$ \\
\hline LACEY & 648,4 & 864,5 & 906,3 & $1.012,6$ & $1.114,9$ \\
\hline Prestige & 969,6 & 991,0 & $1.114,9$ & $1.258,3$ & $1.366,9$ \\
\hline BRS 180 & 703,1 & 969,6 & $1.033,1$ & $1.114,9$ & $1.215,5$ \\
\hline BRS 195 & $1.094,8$ & $1.154,6$ & $1.258,3$ & $1.456,1$ & $1.584,9$ \\
\hline
\end{tabular}

\subsection{INFLUÊNCIA DA ADUBAÇÃO NITROGENADA NOS ESTÁDIOS FENOLÓGICOS}

As doses de nitrogênio provocaram uma diferenciação quanto ao ciclo dos materiais analisados. Ao verificar os resultados, reporta-se que para cada genótipo as doses de $\mathrm{N}$ evidenciaram um atraso ou adiantamento no aparecimento da fase em questão. 
No genótipo AF 9585 (figura 1), a diferenciação ocorreu a partir do aparecimento do emborrachamento na dose de $40 \mathrm{~N}$, provocando um aumento na somatória calórica até o espigamento (1.301,4 graus-dia).

O material genético CEV 98074 (figura 2) mostrou-se bastante homogêneo em seu ciclo, independente da dose, sendo que a dose $20 \mathrm{~N}$ necessitou de menos graus-dias para completar seu ciclo e as doses de 80 e $40 \mathrm{~N}$ de mais graus-dias (1.154,6 ${ }^{\circ} \mathrm{C}, 1.195,5^{\circ} \mathrm{C}$ e $1.215,5^{\circ} \mathrm{C}$, respectivamente).

A variedade americana LACEY (figura 3) também apresentou seu comportamento bastante uniforme, obtendo uma maior diferenciação entre doses durante o surgimento do $1^{\circ}$ nó, sendo a dose de $20 \mathrm{~N}$ a mais precoce $(615,2$ grausdia).

A francesa Prestige (figura 4) demonstrou comportamento regular, com uma diferença na dose $0 \mathrm{~N}$ quanto ao aparecimento da folha bandeira $\left(1.175,1^{\circ} \mathrm{C}\right)$, e na dose $40 \mathrm{~N}$ durante a floração $\left(1.322,4{ }^{\circ} \mathrm{C}\right)$.

As cultivares BRS 180 (figura 5) e BRS 195 (figura 6) mostraram-se mais tardias quando adubadas na dose $40 \mathrm{~N}$ e mais precoces na dose $20 \mathrm{~N}$. A BRS 195 é reconhecidamente de característica mais tardia (Amabile et al., 2008). Em uma mesma dose (40 N), BRS 180 necessitou de 1.301,4 graus-dia e BRS 195, 1.608,4 oC para completar o ciclo. Houve uma redução no somatório calórico quando do surgimento da folha bandeira no tratamento $0 \mathrm{~N}$ para a cultivar BRS 180 . Foram necessários 991,0 graus-dia para esse processo, ao passo que, na dose mais precoce $(20 \mathrm{~N})$, foram demandados $1.012,6$ graus-dia para a conclusão da mesma fase fenológica. 


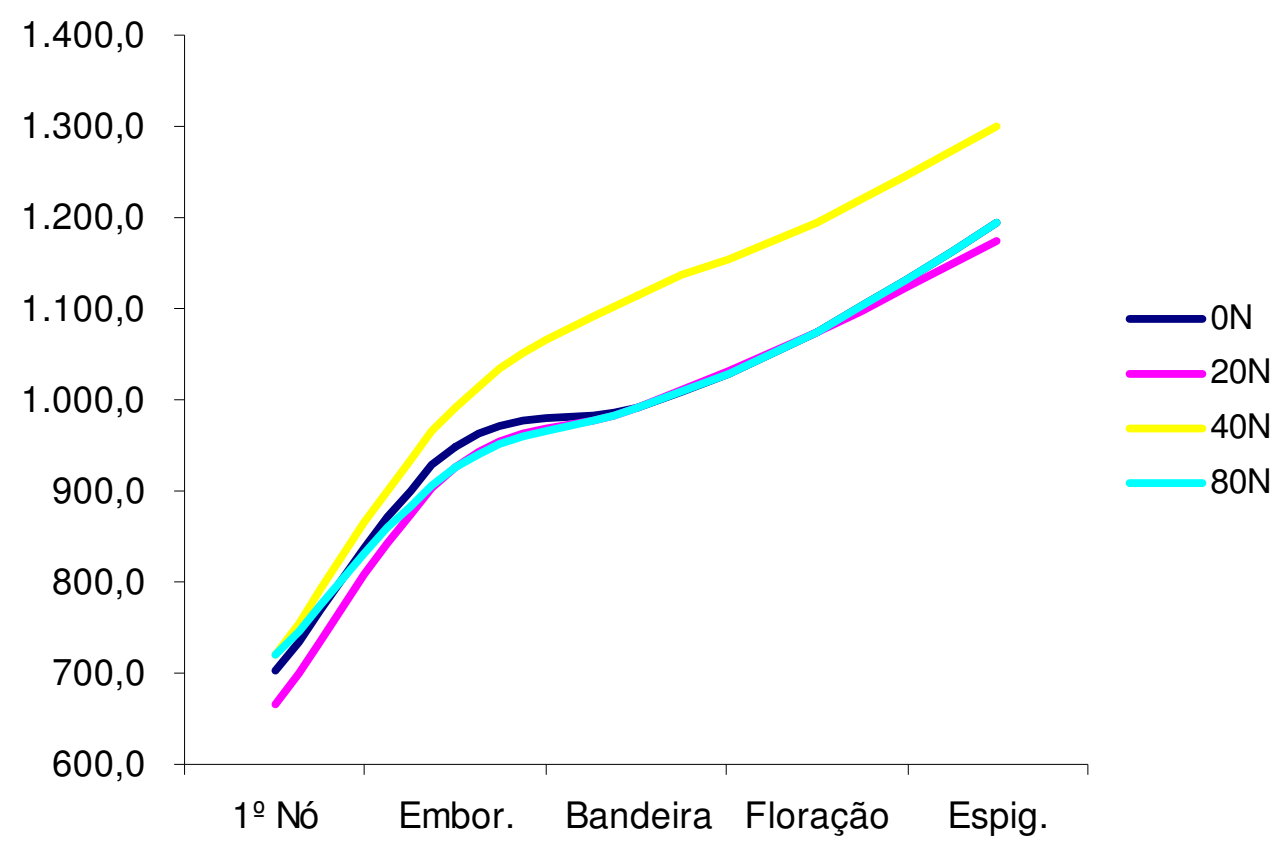

Figura 1. Gráfico em função dos estádios fenológicos para o genótipo AF 9585.

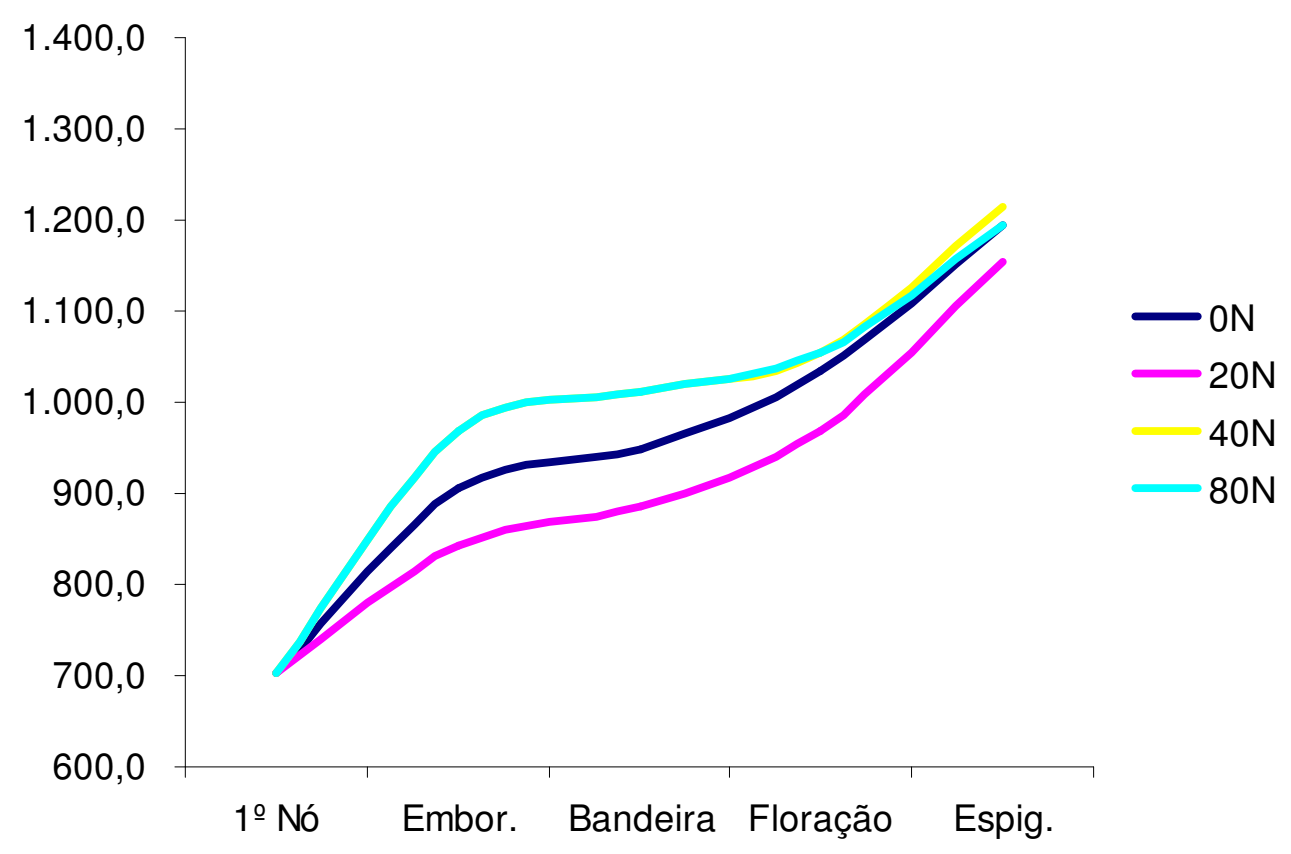

Figura 2. Gráfico em função dos estádios fenológicos para o genótipo CEV 98074. 


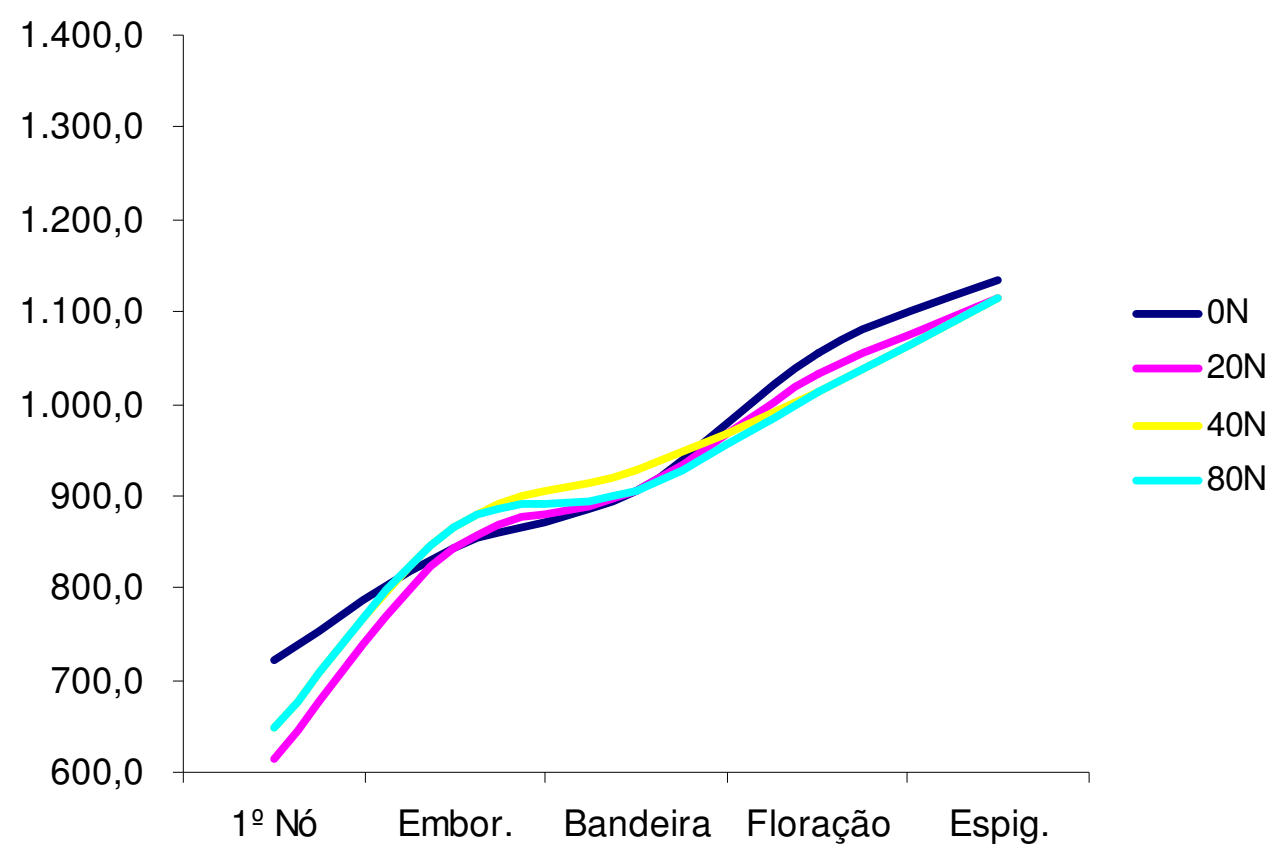

Figura 3. Gráfico em função dos estádios fenológicos para a variedade LACEY.

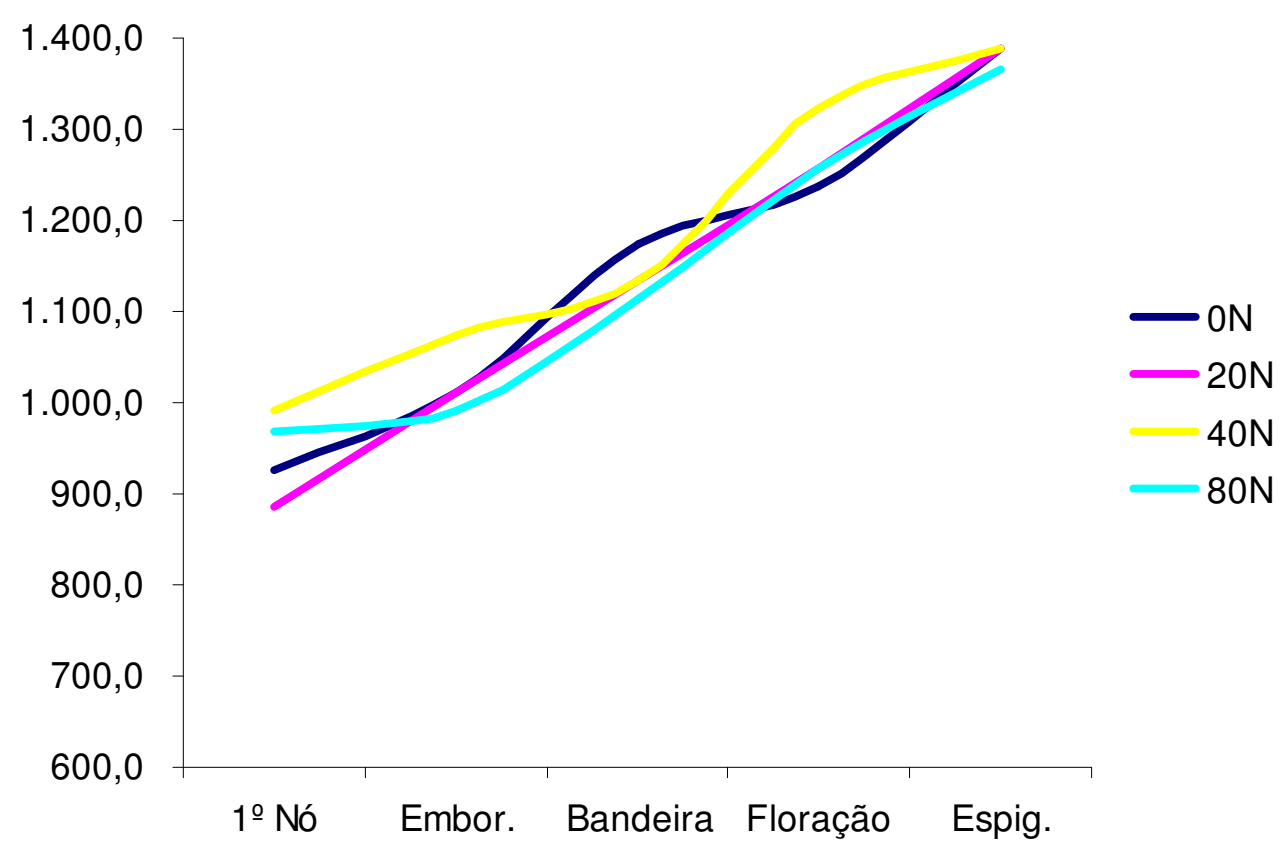

Figura 4. Gráfico em função dos estádios fenológicos para a variedade Prestige. 


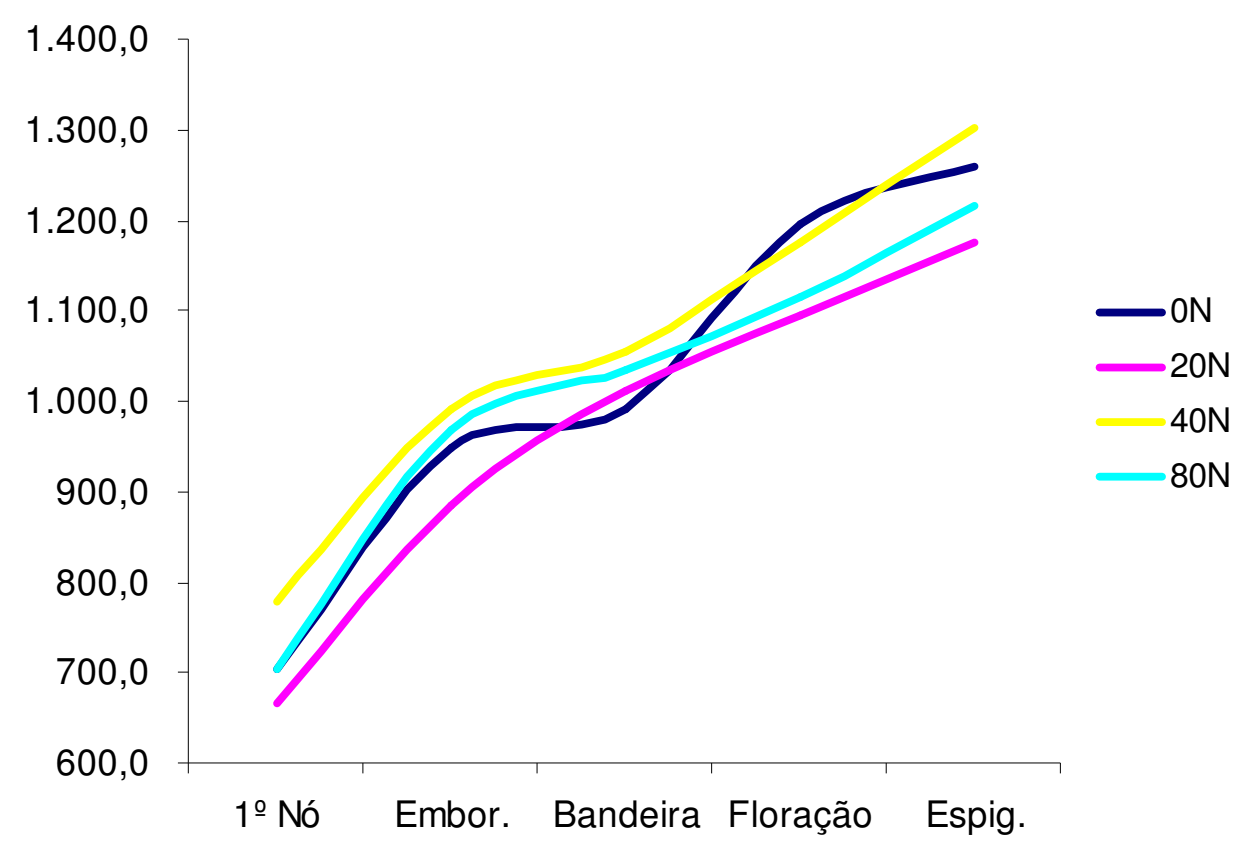

Figura 5. Gráfico em função dos estádios fenológicos para a cultivar BRS 180.

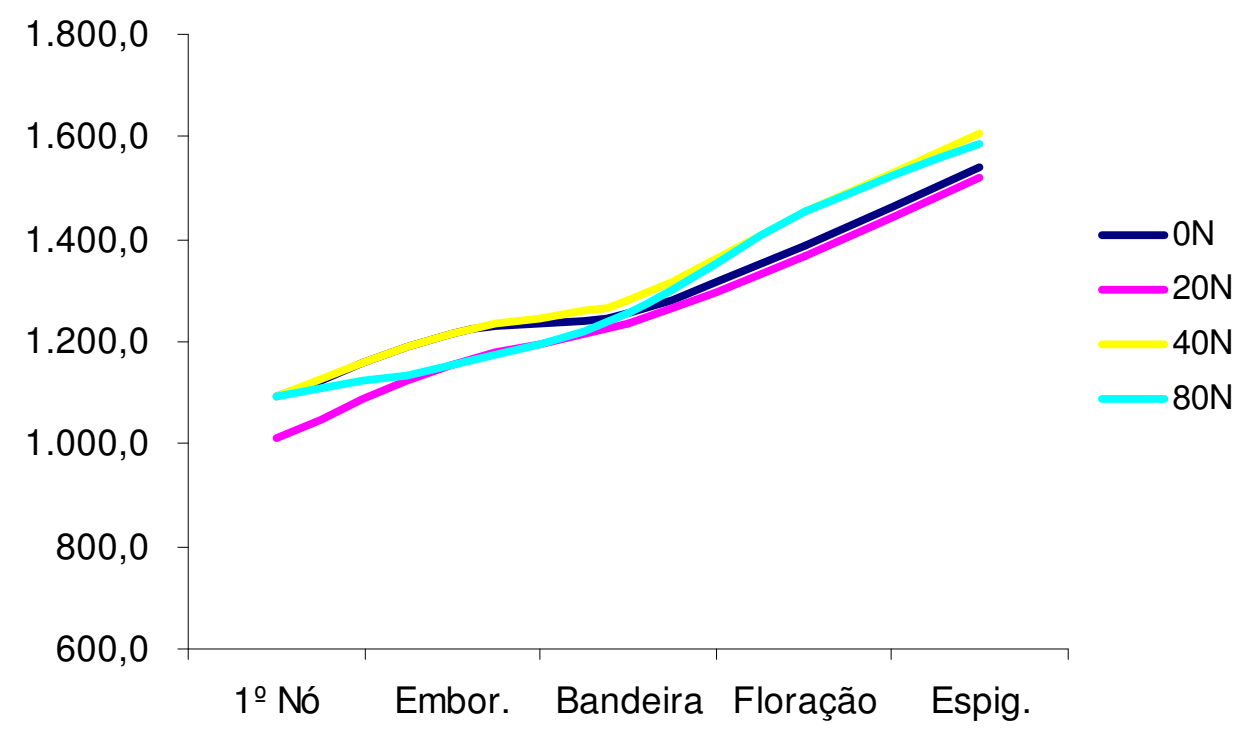

Figura 6. Gráfico em função dos estádios fenológicos para a cultivar BRS 195. 


\section{CONCLUSÕES}

- Com exceção das variedades LACEY e Prestige, os materiais genéticos mostraram-se mais precoces na dose $20 \mathrm{~N}$ e mais tardios na dose $40 \mathrm{~N}$;

- Os genótipos mais precoces foram LACEY (1.114,9 graus-dia, da emergência ao espigamento no tratamento $20 \mathrm{~N}$ ) e CEV 98074 (1.154,6 graus-dia da emergência ao espigamento na dose $20 \mathrm{~N}$ );

- A cultivar mais tardia foi a BRS 195 , com $1.608,4 \stackrel{\circ}{\circ}$ da emergência ao espigamento no tratamento $40 \mathrm{~N}$;

- O nitrogênio influencia no surgimento das fases fenológicas e no ciclo da planta, aumentando-o ou diminuindo-o em função da dose apregoada. 


\section{REFERÊNCIAS BIBLIOGRÁFICAS}

ADÁMOLI, J.; MACÊDO, J.; AZEVEDO, L. G. de; MADEIRA NETO, J. S. Caracterização da região dos Cerrados. In: GOEDERT, W. J. (Ed.) Solos dos Cerrados: tecnologias e estratégias de manejo. Planaltina: Embrapa-CPAC; São Paulo, SP: Nobel, 1986. p. 33-98.

AMABILE, R. F.; SILVA, D. B. da; GUERRA, A. F. Cevada irrigada e realidade no Cerrado. Revista Guinness, Formosa, v. 1, n. 2, nov./dez. 2002. p. 6-8.

AMABILE, R. F.; MINELLA, E.; OLIVEIRA, F. A.; GUERRA, A. F.; SILVA, D. B. da; LOPES, F. G.; RIBEIRO JÚNIOR, W. Q. Avaliação do comportamento de genótipos de cevada hexástica irrigada no Cerrado. In: REUNIÃO ANUAL DE PESQUISA DE CEVADA, 24., 2004, Passo Fundo. Anais... Passo Fundo: Embrapa Trigo, 2004a. p.134-141.

AMABILE, R. F.; SILVA, D. B. da ; GUERRA, A. F. Cevada irrigada conquista Cerrado. 2004b. Disponível em: <http://www.embrapa.br/imprensa/noticias/2000/agosto/bn.2004-1125.9407345058/>. Acesso em: jun. 2009.

AMABILE, R. F.; SILVA, D. B. da; GUERRA, A. F. Cevada irrigada em áreas de Cerrado no Brasil central. Circular Técnica, 26. Planaltina, DF. Embrapa, 2004c. 4 p.

AMABILE, R. F.; MINELLA, E.; ARAÚJO, D. S.; MONTEIRO, V. A.; INÁCIO, A. A. do N.; GUERRA, A. F.; RIBEIRO JÚNIOR, W. Q. Avaliação de introduções de linhagens de cevada industriais de coleções nacionais e internacionais, em sistema irrigado In: REUNIÃO NACIONAL DE PESQUISA DE CEVADA, 26., 2007, Passo Fundo. Anais... Passo Fundo: Embrapa Trigo, 2007. p. 379-394.

AMABILE, R. F.; MINELLA, E.; GUERRA, A. F.; SILVA, D. B. da; ALBRECHT, J. C.; ANTONIAZZI, N. BRS Deméter: nova cultivar de cevada cervejeira irrigada para 0 
Cerrado do Brasil Central. Pesquisa Agropecuária Brasileira. Brasília, v. 43, n. 9 , 2008. p. 1247-1249.

ANDERSON, P. M.; OELKE, E. A.; SIMMONS, S.R. Growth and development guide for spring barley. University of Minnesota, 2002. Disponível em: <http://www.extension.umn.edu/distribution/cropsystems/DC2548.html\#fig1>. Acesso em: jun. 2009.

ANGHINONI, I. Adubação nitrogenada nos estados do Rio Grande do Sul e Santa Catarina. In: SANTANA, M. B. M. Adubação nitrogenada no Brasil. Ilhéus: CEPLAC/SBSC; 1986. p 1-18.

ARAÚJO, G.A.A.; VIEIRA,C.; MIRANDA, G.V. Efeito da época de aplicação do adubo nitrogenado em cobertura sobre o rendimento do feijão, no período de outono-inverno. Revista Ceres. Viçosa, v.41, n. 236, 1994. p. 442-450.

ASSAD, E. D. (Ed.) Chuva nos Cerrados: análise e espacialização. Brasília: Embrapa/SPI, 1994. 423 p.

BALDANZI, G.; BAIER, A. C.; FLOSS, E. L.; MANARA, W.; FELKL MANARA, N. T.; VEIGA, P.; TARRAGÓ, M. F. S. As lavouras de inverno 2. Rio de Janeiro: Globo, 1988. p. 16-67.

BALL, D. A.; KLEPPER, B.; RYDRYCH, D. J. Comparative aboveground development rates for several annual grass weeds and cereal grains. Weed Science, v. 43, 1995. p. 410-416.

BAYMA, C. Trigo. Rio de Janeiro: Serviço de Informação Agrícola, v. 1, 1960 (Estudos técnicos n.․ 14). p. 13.

BOTHMER, R. von; JACOBSEN, N.; BADEN, C.; JORGENSEN, R.B.; LINDELAURSEN, I.B. An ecogeographical study of the genus hordeum. Rome: IBPGR, 1991. 127p. 
BRASIL. Ministério da Agricultura e Abastecimento. Portaria 691, de 22 de novembro de 1996. Brasília, 1996.

BRITTO, D. P. P. S.; CASTRO, A. F.; COSTA, F.A.; NERY, C. Ensaio de adubação de milho em Latossolo Vermelho-Amarelo sob vegetação do Cerrado. Pesquisa Agropecuária Brasileira, Série Agronomia, Rio de Janeiro, v.6, 1971. p. 203-207.

BROCKLEHURST, P.A. Factors controlling grain wheight in wheat. Nature, v.266, 1977. p.348-349.

BRUNINI, O.; LISBÃO, R. S.; BERNARDI, J. B.; FORNASIER, J. B.; PEDRO JÚNIOR, M. J. Temperatura-base para alface cultivar "White Boston", em um sistema de unidades térmicas. Bragantia, Campinas, v. 35, n. 19, 1976. p. 213-219.

CALEY, C.Y.; DUFFUS, C.M.; JEFFCOAT, B. Effects of elevated Temperature and Reduced Water Uptake on Enzymes of Starch Synthesis in Developing Wheat Grains. Australian Journal of Plant Physiology, v.17, 1990. p.431-439.

CAMARGO, M. B. P. de; BRUNINI, O.; MIRANDA, M. A. C. Temperatura-base para cálculo dos graus dia para cultivares de soja em São Paulo. Pesquisa Agropecuária Brasileira, Brasília, v. 22, n. 2, 1987. p. 115-121.

CAMARGO, F.A. de O. Fracionamento e dinâmica do nitrogênio orgânico em solos do Rio Grande do Sul. Porto Alegre -RS. 152 p. Tese (Doutorado em Ciência do Solo) - Curso de pós-graduaçâo em Agronomia, Universidade Federal do Rio Grande do Sul, 1996.

CAO, W.; MOSS, D. N. Phyllochron change in winter wheat with planting date and environmental changes. Agronony Journal, v. 83, 1991. p. 396-401.

CARVALHO, A. M. de. Uso de plantas condicionadoras com incorporação no solo: composição química e decomposição dos resíduos vegetais; disponibilidade de fósforo e emissão de gases. 199 p. Tese (Doutorado) Universidade de Brasília, Brasília, 2005. 
CESTARO, L. A. Ecologia do estrato herbáceo da mata de araucária da Estação Ecológica de Aracuri, Esmeralda, Rio Grande do Sul. 1984. 110 f. Dissertação (Mestrado em Ecologia) - Instituto de Biociências, UFRGS, Porto Alegre.

CHAPMAN, S. R.; CARTER. L. P. Crop production: principles and practices. San Francisco: Montana Stare University, 1976. p. 311-324.

CONAB. Análise de safras. Disponível em: <http://www.conab.gov.br>. Acesso em: jul. 2008.

CORREIA, J. R., REATTO, A., SPERA, S.T. Solos e suas relações com o uso e o manejo. In: SOUZA, D. M. G., LOBATO, E. Cerrado: correção do solo e adubação. 2 ed. Brasília, DF: EMBRAPA Informação Tecnológica. 2004. 416p.

COSTA, C. S. B.; SEELIGER, U.; CORDAZZO, C. V. Distribution and phenology of Andropogon arenarius hackel on coastal dunes of Rio Grande do Sul, Brazil. Revista Brasileira de Biologia, v. 48, n. 3, 1988, p. 527-536.

DELOUCHE, J.C. Metodologia de pesquisa em sementes. III. Vigor, envigoramento e desempenho no campo. Revista Brasileira de Sementes, Brasília, v.3, n.2, 1981. p. 57-64.

DIAMOND, J. Guns, germs and steel. London: Vintage, 1998.

EITEN, G. Vegetação do Cerrado. In: PINTO, M. N. Cerrado. Brasília: Editora Universidade de Brasília, 1993. p.17-73.

EMBRAPA CERRADOS. Cevada BRS 180: primeira cultivar de cevada cervejeira para o sistema de produção irrigado do Cerrado. Planaltina: Embrapa Cerrados, 1999. Folder Técnico. 
EMBRAPA, Agência de Informações. Bioma Cerrado. 2007. Disponível em: http://www.agencia.cnptia.embrapa.br/Agencia16/AG01/Abertura.html>. Acesso em: jul. 2008.

FAGUNDES, M. H. Sementes de cevada. 2003. Disponível em: $<w w w . c o n a b . g o v . b r>$. Acesso em: jul. 2008. 14 p.

FAOSTAT. Statistical databases. Disponível em: <http://faostat.fao.org>. Acesso em: jul. 2008.

FONTOURA, S.M.V.; MUNDSTOCK, C.M.; MORAES, P. R. Efeito da época de aplicação de nitrogênio em cobertura e da densidade de plantas no rendimento de duas cultivares de cevada. XXI reunião anual de pesquisa de cevada. Anais e Ata... Passo Fundo, RS. Vol. I, 2001. p. 583-594.

FONTOURA, S.M.V.; MORAES, P. R. Efeito do nitrogênio aplicado em cobertura, sobre resteva de soja, no rendimento de grãos de quatro cultivares de cevada. XXIII reunião anual de pesquisa de cevada. Anais e Ata... Passo Fundo, RS. 2003. p. 385-392.

FOURNIER, L. A. El dendrofenograma, una representación gráfica del comportamiento fenológico de los árboles. Turrialba, v. 26, n. 1, 1976. p. 96-97.

FREITAS, L. M. M. de; MIKKELSEN, D.S.; McLUNG, A. C.; LOTT, W.L. Efeito de calagem e adubação na produção de algodão, milho e soja em três solos de campo Cerrado. In: SIMPÓSIO SOBRE O CERRADO, 1, 1963, São Paulo. Anais... São Paulo: Edgard Blucher, 1963. p. 283-314.

FREITAS, L. M. M. de; LOBATO, E.; SOARES, W. V. Experimentos de calagem e adubação em solos sob vegetação de Cerrado do Distrito Federal. Pesquisa Agropecuária Brasileira, Série Agronomia, Rio de Janeiro, v. 6, 1971. p. 81-88. 
GEAR, N. Evaluación de la respuesta al fotoperíodo en cultivares de cebada cervecera. In. REUNIÃO ANUAL DE PESQUISA DE CEVADA, 25, 2005, Passo Fundo. Anais... Passo Fundo: Embrapa Trigo, 2005.

GOEDERT, W. J. Potencial agricola dos Cerrados. In: SIMPOSIO SOBRE O POTENCIAL AGRICOLA DOS CERRADOS, 1985, Goiania. Trabalhos apresentados. Goiania: EMGOPA / Campinas: Fundacao Cargill, 1985. p.1-2.

GROVE, L.T.; RITCHEY, K. D.; NADERMAN JUNIOR JUNIOR, C. Nitrogen fertilization of maize on an Oxisol of the Cerrado of Brazil. Agronomy Journal, Madison, v.72, 1980. p. 261-265.

GUERRA, A. F.; SILVA, E. M. da; AZEVEDO, J. A. de. Estabelecimento do momento de irrigação em trigo e cevada baseado em níveis de tensão de água em Latossolo dos Cerrados. In: EMBRAPA. Centro de Pesquisa Agropecuária dos Cerrados (Planaltina, DF). Relatório técnico anual do Centro de Pesquisa Agropecuária dos Cerrados 1982/1985. Planaltina, 1987. p. 227-231.

GUERRA, A. F. Manejo de irrigação da cevada sob condições de Cerrado visando o potencial de produção. Pesquisa Agropecuária Brasileira, Brasília, v.29, n.7, 1994. p. 1111-1118.

GUERRA, A. F. Tensão de água no solo: efeito sobre a produtividade e qualidade dos grãos de cevada. Pesquisa Agropecuária Brasileira, Brasília, v.30, n.2, 1995. p. 245-254.

HARLAN, J.R. On the origin of barley. In: Barley: origin, botany, culture, winterhandiness, genetics, utilization and pests. USDA-ARS Agricultural Handbook no 338. 1979.

HAUN, J. R. Visual qualification of wheat development. Agronomy Journal, v. 65, 1973. p. 116-117. 
IBAMA: Agricultura Sustentável. Brasília: Ministério do Meio Ambiente; Instituto Brasileiro do Meio Ambiente e dos Recursos Natuarais Renováveis; Consórcio Museu Emílio Goeldi, 2000. p. 190.

INFELD, J. A.; SILVA, J. B. da. Somas térmicas da duração da faze vegetativa do arroz irrigado (Oyiza sativa L.). In: CONGRESSO BRASILEIRO DE AGROMETOROLOGIA, 5., Belém. Anais... Belém: SBA, 1987. p. 160-161.

KERNICH, G. C.; SLAFER, G. A.; HALLORAN, G. M. Barley development as affected by rate of change of photoperiod. Journal of Agricultural Science, Cambridge, v. 124, 1995. p. 379-388.

KIRBY, E. J. M.; APPLEYARD, M.; FELLOWS, G. Effects of sowing date on the temperature response of leaf emergence and leaf size in barley. Plant Cell and Environment, v. 5, 1982. p. 477-484.

LARCHER, W. Ecofisiologia vegetal. São Carlos: RiMa, 2000. p. 207.

LARGE, E. C. Growth stages in cereals illustration of the feekes scale. Plant Pathology, v. 3, 1954. p. 128-129.

LIMA, J. E. F. W.; SANO, E. E.; SILVA, E. M. da; LOPES, T. S. S. Levantamento da área irrigada por pivô-central no Cerrado por meio da análise de imagens de satélite: uma contribuição para a gestão dos recursos hídricos. In: SIMPÓsIO DE RECURSOS HÍDRICOS DO NORTE E CENTRO-OESTE, 1., 2007, Cuiabá. Anais... Cuiabá: ABRH, 2007.

LOPES, A. S. Solos sob "Cerrado": características, propriedades e manejo. Piracicapa: Instituto da Potassa \& Fosfato: Instituto Internacional da Potassa, 1983.

MALAVOLTA, E.; KLIEMANN, H. J. Desordens nutricionais no Cerrado. Piracicaba: Potafos, 1985. $136 \mathrm{p}$. 
MALAVOLTA, E. Manual de nutrição mineral de plantas. São Paulo: Editora Agronômica Ceres, 2006. 638 p.

MANTOVANI, W.; MARTINS, F. R. Variações fenológicas das espécies do Cerrado, da reserva biológica de Mogi-Guaçu, Estado de São Paulo, SP. Revista Brasileira de Botânica, 11. 1988. p. 101-112

MAPA. Anuário 2005. Disponível em <http://www.agricultura.gov.br>. Acesso em: 26 jul. 2008.

MARCOS FILHO, J. Fisiologia de sementes de plantas cultivadas. Piracicaba: FEALQ, 2005. 495 p.

MATSUSHIMA, S. Crop science in rice: theory of yield determination and its application. Tokyo: Fuji Publishing, 1970. 379p.

MCMASTER, G.S. Phenology, development and growth of the wheat (Triticum aestivum L.) shoot apex: a review. Advances in Agronomy, Madison, v.59, 1997. p.63-118.

MINELLA, E. Cevada brasileira: situações e perspectivas. Passo Fundo: Embrapa Trigo, 1999a. Comunicado Técnico Online, 23. Disponível em: <http://www.cnpt.embrapa.br/biblio/p_co23.htm>. Acesso em: jun. 2009.

MINELLA, E. Desafios e potencialidades do melhoramento genético de cevada no Brasil. In: REUNIÃO ANUAL DE PESQUISA DE CEVADA, 21., 2001, Passo Fundo. Anais e ata... Passo Fundo: Embrapa Trigo, 2001. v. 1, p. 31-40.

MINELLA, E. Melhoramento de Cevada. In: BORÉM, A. Melhoramento de espécies cultivadas. Viçosa, MG: UFV, 1999b. p.253-272.

MINELLA, E.; CIULLA, C.; PANISSON, E.; WOBETO, C.; NOVATZKI, M. Avaliação de safra no Brasil em 2004. In. REUNIÃO ANUAL DE PESQUISA DE CEVADA, 25., 
2005, Guarapuava. Anais... Guarapuava: Fundação Agrária de Pesquisa Agropecuária, 2005.

MINELLA, E.; CIULLA, C.; OPPELT, D.; WOBETO, C.; NOVATZKI, M. Safra brasileira de cevada: resultados 2006. In: REUNIÃO NACIONAL DE PESQUISA DE CEVADA, 26, 2007, Passo Fundo. Anais... Passo Fundo: Embrapa Trigo, 2007. p. $102-105$.

MUNDSTOCK, C. M. Planejamento e manejo integrado da lavoura de trigo. Porto Alegre: ed. Autor, 1999. 228 p.

NIMER, E. Climatologia do Brasil. Rio de Janeiro: IBGE, 1989. 422 p.

REATTO, A.; CORREIA, J. R.; SPERA, S. T.; Solos do bioma Cerrado: aspectos pedológicos. In: SANO, S. M.; ALMEIDA, S. P. (Ed.) Cerrado: ambiente e flora. Planaltina, DF: EMBRAPA-CPAC, 1998. p. 47-83.

OMETTO, J. C. Bioclimatologia vegetal. São Paulo: Ed. Agronômica Ceres, 1981. $440 \mathrm{p}$.

PEREIRA, A. R.; ANGELOCCI, L. R.; SENTELHAS, P. C. Agrometereologia: fundamentos e aplicações práticas. Guaíba, RS: Livraria e Editora Agropecuária Ltda, 2002. 478 p.

PERUZZZ, G. Avaliação do rendimento de cevada cervejeira em função de diferentes doses e fontes de nitrogênio em 1986. In: EMBRAPA. Centro Nacional de Pesquisa de Trigo (Passo Fundo, RS). Resultados de pesquisa do Centro Nacional de Pesquisa de Trigo apresentados na VI, VII e VIII reuniões anuais de pesquisa de cevada. Passo Fundo, RS: EMBRAPA-CNPT, 1988. p. 97-104.

PERUZZO, G. Efeito de nitrogênio no rendimento de grãos de quatro genótipos de cevada, em 2000. XXI reunião anual de pesquisa de cevada. Anais e Ata... Passo Fundo, RS. Vol. II, 2001. p. 599-604. 
POEHLMAN, J. M. Breeding field crops. New York: Henry Holt and Company, Inc., 1959. p. 151-173.

POLETO, N.; ALFONSO, C.W.; PIANA, A.T.; GROHS, D.S.; MUNDSTOCK, C.M. Resposta da cevada a doses de $\mathrm{N}$ em cobertura e a disponibilidade de $\mathrm{N}$ no solo e teores na planta. XXIII reunião anual de pesquisa de cevada. Anais e Ata. Passo Fundo, RS. 2003. p. 345- 351.

QUINTANA, J. O. Evalution of two procedures for screening legume green manure as nitrogen souces to succeeding corn. 179 p. Thesis (Ph.D) - Cornell University, Ithaca, 1987.

RATTUNDE, H.F. \& FREY, K.J. Nitrogen harvest index in oats: its repeatability and association with adaptation. Crop science, Madison. V.26, n.3, 1986. p. 606-610.

RESENDE, M.; CURI, N.; REZENDE, S.B.; CORRÊA, G.F. Pedologia: Base para distinção de ambientes. 4.ed. Viçosa: NEPUT, 2002.

RIBEIRO, J. F. \& WALTER, B. M. T. 1998. Fitofisionomias do Bioma Cerrado. In: S. M. Sano \& S. P. Almeida (eds.). Cerrado: ambiente e flora. Embrapa Cerrados, Planaltina. p. 87-166.

SAARIKKO, R. A.; CARTER, T. R. Phenological development in spring cereals: response to temperature and photoperiod under northern conditions. European Journal of Agronomy, v. 5, 1995. p. 59-70.

SAVIN, R.; STONE, P. J.; NICOLAS, M. E.; WARLAW, I. F. Grain growth and malting quality of barley: 1- Effects of heat stress and moderately high temperature. Australian Journal of Agricultural Research, Collingwood, v. 48, 1997. p. 615-624.

SILVA, A. R.; ANDRADE, J. M. V. A cultura de cevada na estação seca com irrigação nos Cerrados do DF. Pesquisa Agropecuária Brasileira, Brasília, v. 4, n. 3, 1985. p. 305-316. 
SMITH, C. W. Crop Production: evolution, history and tecnology. Department of Soil \& Crop Science. Texas A\&M University.1995. p. 174-219.

SOUZA, J. L. Avaliação agroclimática de quatro microrregiões do Estado de Minas Gerais para alguns cultivares de Feijão (Phaseolus vulgaris). 1989. $70 \mathrm{f}$. Dissertação (Mestrado em Agrometeorologia) - Universidade Federal de Viçosa, Minas Gerais.

SOUZA, P. R. Alguns aspectos de influência do clima e temperatura sobre a cultura do arroz irrigado no sul do Brasil. Lavoura Arrozeira, Porto Alegre, v. 43, n. 389, 1990. p. 9-11.

STARLING, T.M. Barley. In: FEHR, W.R.; HADLEY, H.H. Hybridization of crop plants. Madison: American Society of Agronomy; Crop Science Society of America, 1980. p.189-193.

STRAND, E. Base temperature levels in heat sum calculations. Acta Agriculturæ Scandinavica, v. 37, 1987. p. 279-286.

SUHET, A. R.; PERES, J. R. R.; RITCHEY, K. D. Adubação nitrogenada em solos de Cerrado. In: SIMPÓSIO SOBRE O CERRADO; SAVANAS: ALIMENTO E ENERGIA, 6, 1982, Brasília, DF. Anais... Planaltina, DF: EMBRAPA-CPAC, 1988. p. 79-85.

TALORA, D. C.; MORELLATO, P. C. Fenologia de espécies arbóreas em floresta de planície litorânea do sudeste do Brasil. Revista Brasileira de Botânica, v. 23, n. 1, 2000. p. 13-26.

TEIXEIRA, M.C.C.; RODRIGUES, O.; WOLF, W.M. Efeito de doses e épocas de aplicação de nitrogênio no acamamento e em características de cevada. XXIII reunião anual de pesquisa de cevada. Anais e Ata... Passo Fundo, RS. p. 359-365, 2003.

VAN SANFORD, D.A. Variation in kernel growth characters among soft red winter wheats. Crop Science, v.25, n.4, 1985. p.626-630. 
WAMSER, A. F.; MUNDSTOCK, C. M. Adubação nitrogenada em estádios fenológicos de cevada, cultivar "MN 698". Ciência Rural, v. 37, n. 4, 2007. p. $942-$ 948.

WARRINGTON, I. J.; KANEMASU, E. T. Corn growth response to temperature and photoperiodo. I. Seedling emergence, tasel iniciation and anthesis. Agronomy Journal, Madison, v. 75, 1983. p. 749-754.

WYCH, R.D.; McGRAW, R.L.; STUTHMAN, D.D. Genotype $x$ year interaction for lenght and rate of grain filling in oats. Crop Science, v.22, n.6, 1982. p.1025-1028.

ZADOKS, J. C.; CHANG, T. T.; KONZAK, C. F. A decimal code for the growth stages of cereals. Weed Reaserch, v. 14, 1974. p. 415-421.

ZOHARY, D.; HOPF, M. Domestication of plants in the Old World: The origin and spread of cultivated plants in West Asia, Europe and the Nile Valley. Oxford: Clarendon Press, 1993. 


\section{ANEXOS}

$\mathbf{O N}$

$20 \mathrm{~N}$
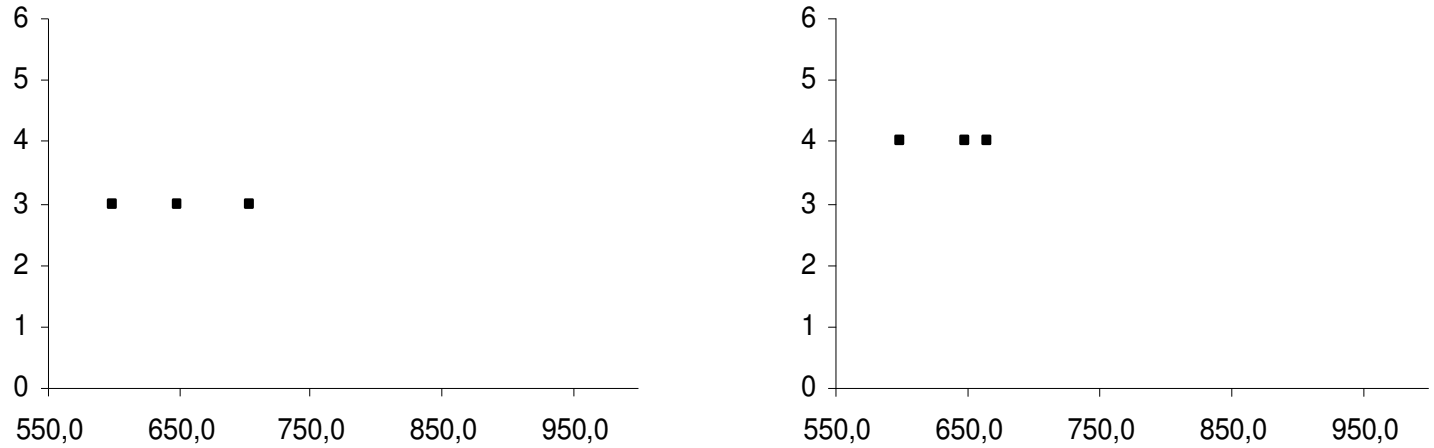

$40 \mathrm{~N}$

$80 \mathrm{~N}$
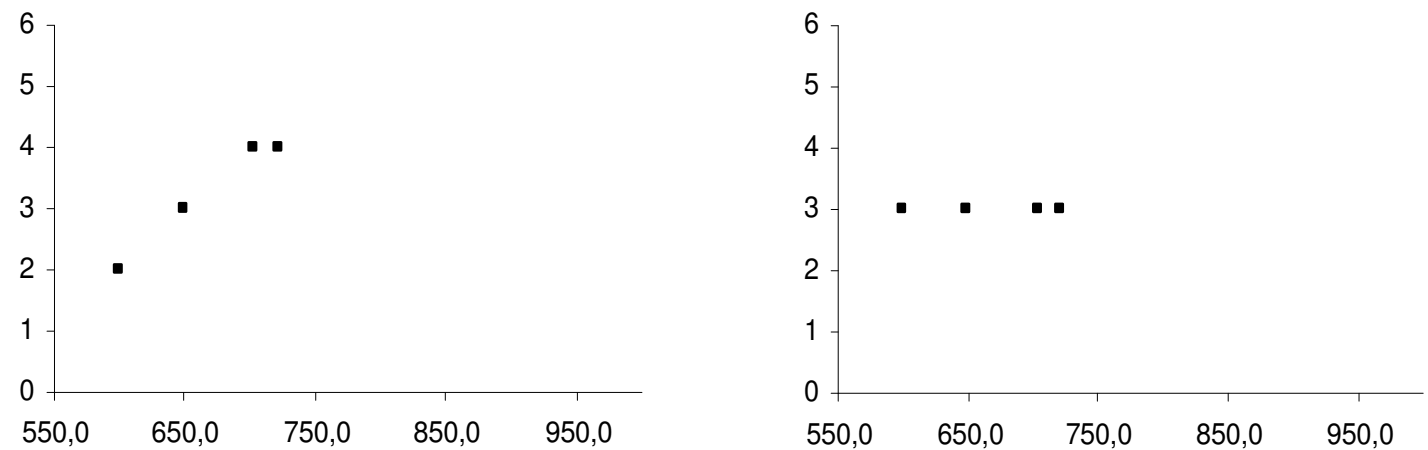

Figura 7. Número de folhas, em função do somatório calórico, do dia 08/07/2005 (1 $1^{\text {a }}$ medição) ao surgimento do 1ํ nó para o genótipo AF 9585, nas quatro doses analisadas. 

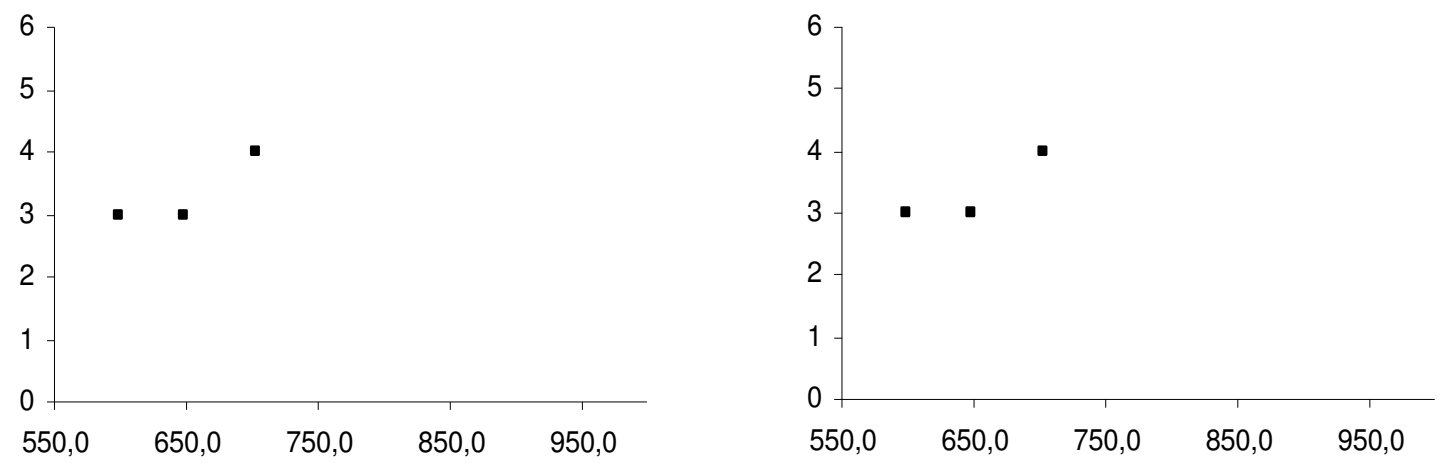

$40 \mathrm{~N}$

$80 \mathrm{~N}$
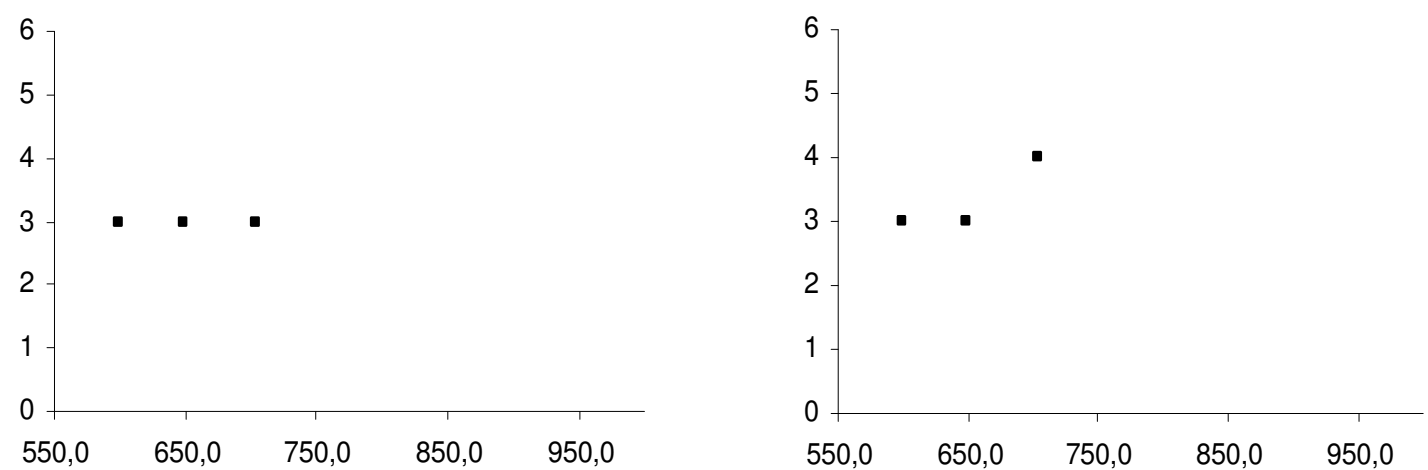

Figura 8. Número de folhas, em função do somatório calórico, do dia 08/07/2005 (1ª medição) ao surgimento do 1 ํㅡó para o genótipo CEV 98074, nas quatro doses analisadas. 

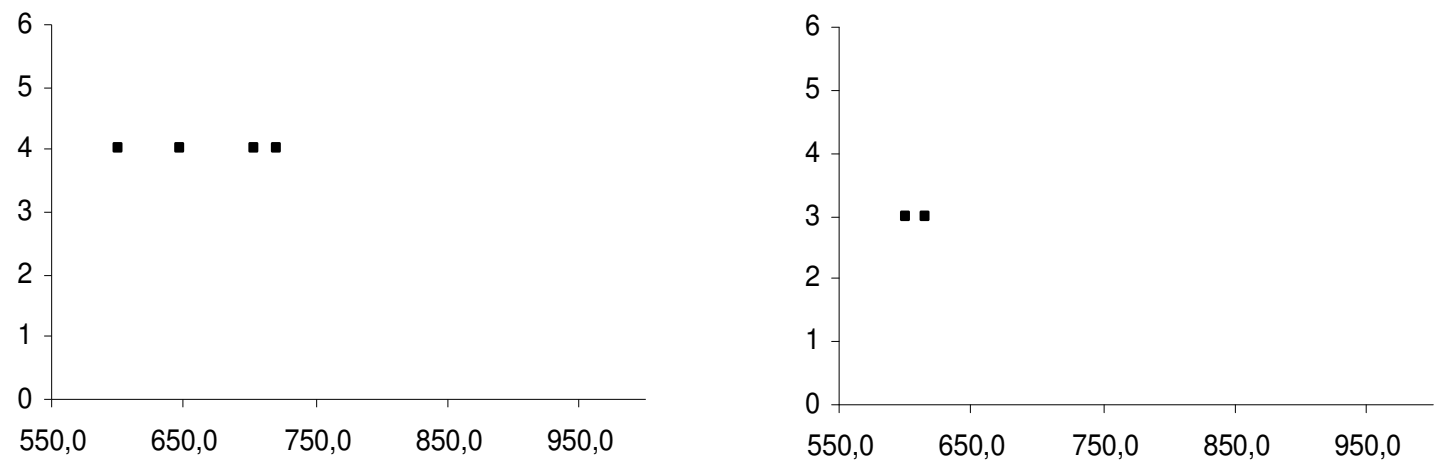

$40 \mathrm{~N}$

$80 \mathrm{~N}$
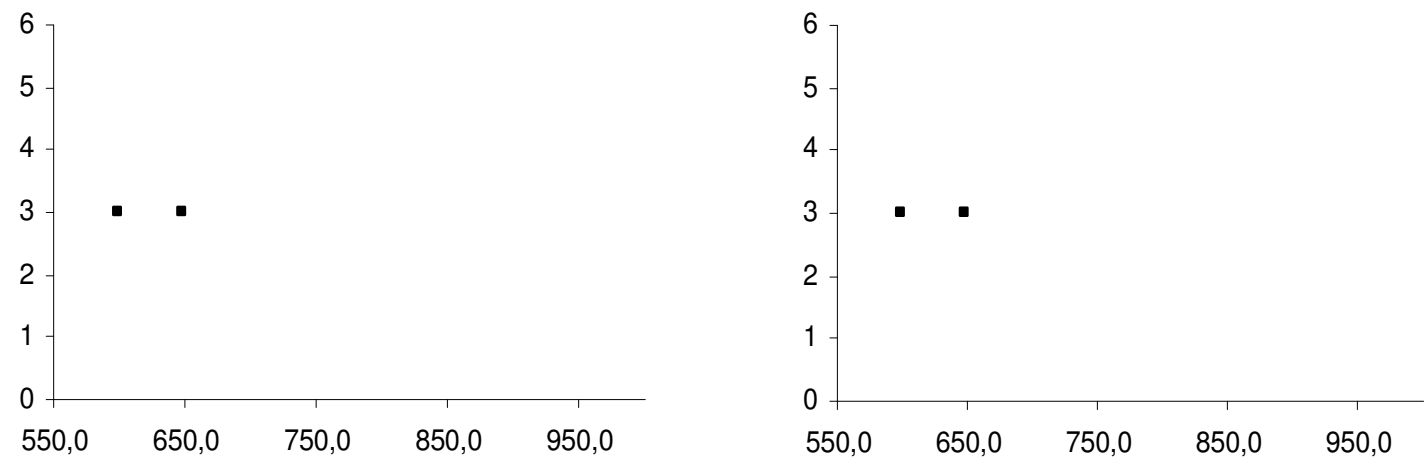

Figura 9. Número de folhas, em função do somatório calórico, do dia 08/07/2005 (1 $1^{\text {a }}$ medição) ao surgimento do 1 - nó para a variedade LACEY, nas quatro doses analisadas. 
$\mathbf{O N}$

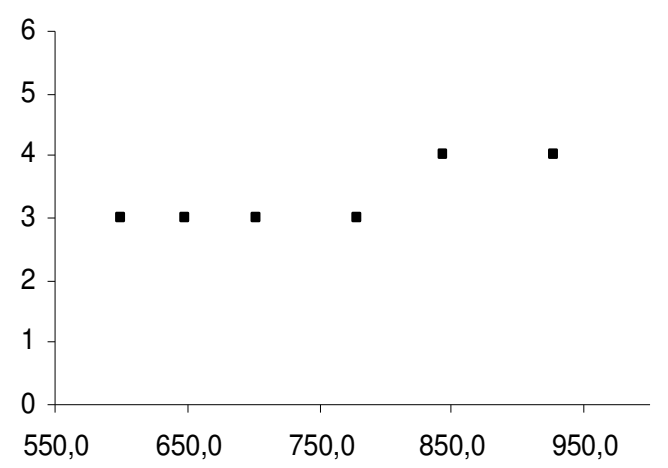

$40 \mathrm{~N}$

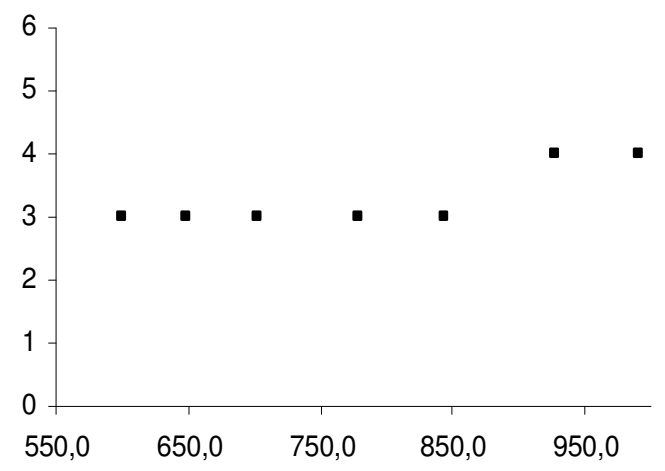

$20 \mathrm{~N}$

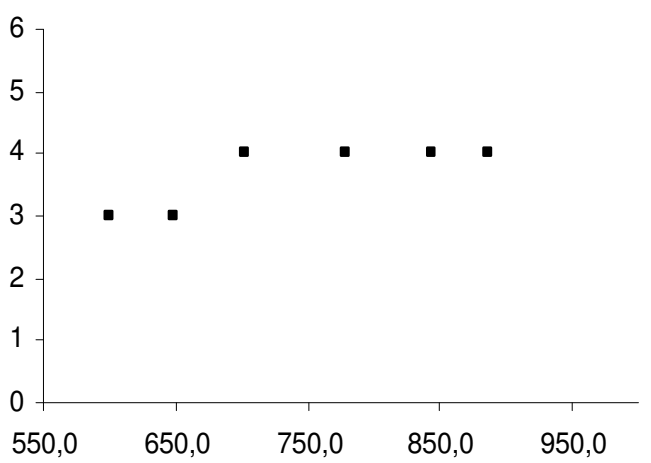

$80 \mathrm{~N}$

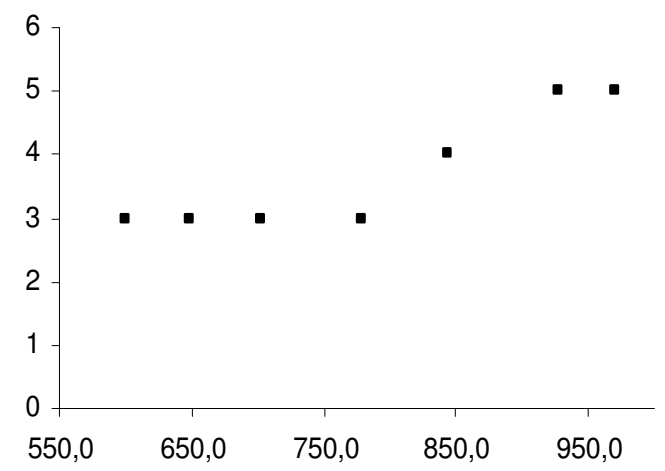

Figura 10. Número de folhas, em função do somatório calórico, do dia 08/07/2005 (1ª medição) ao surgimento do $1^{\circ}$ nó para a variedade Prestige, nas quatro doses analisadas. 

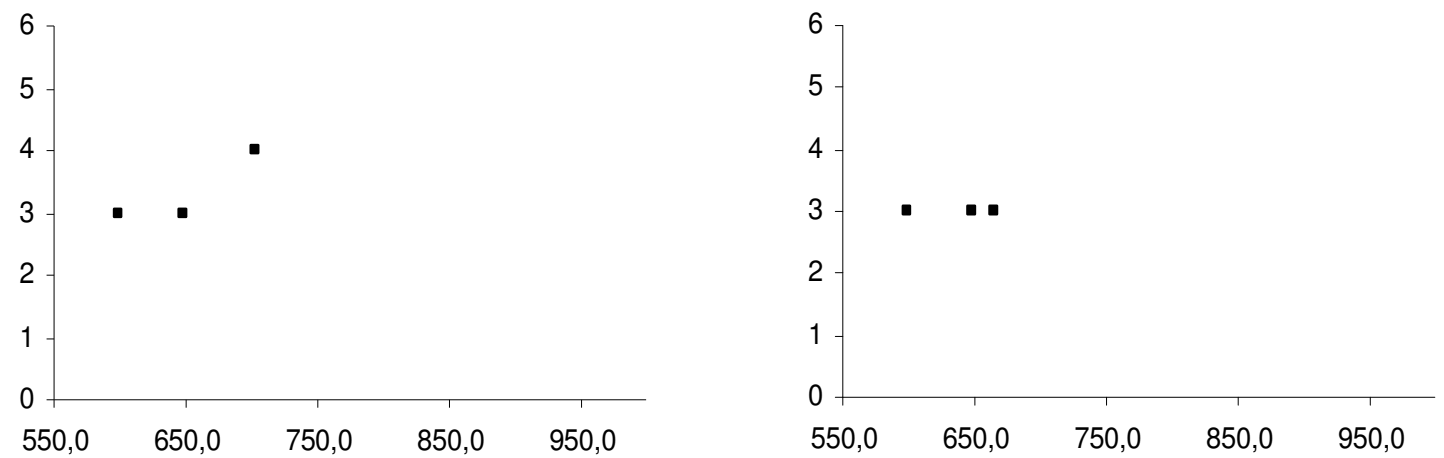

$40 \mathrm{~N}$

$80 \mathrm{~N}$
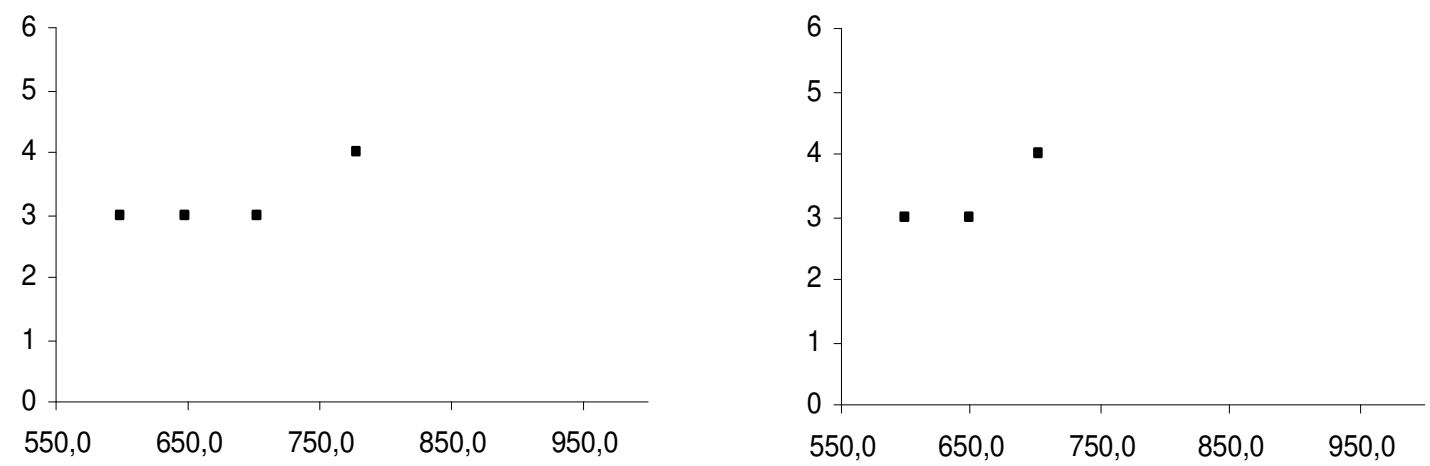

Figura 11. Número de folhas, em função do somatório calórico, do dia 08/07/2005 (1ª medição) ao surgimento do 1ํㅡó para a cultivar BRS 180, nas quatro doses analisadas. 
ON

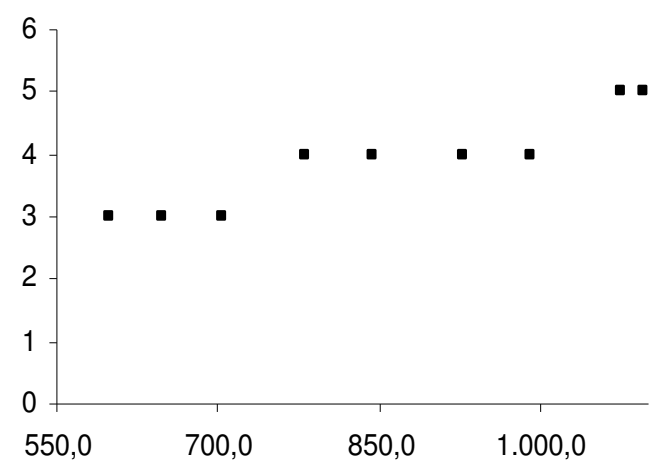

$40 \mathrm{~N}$

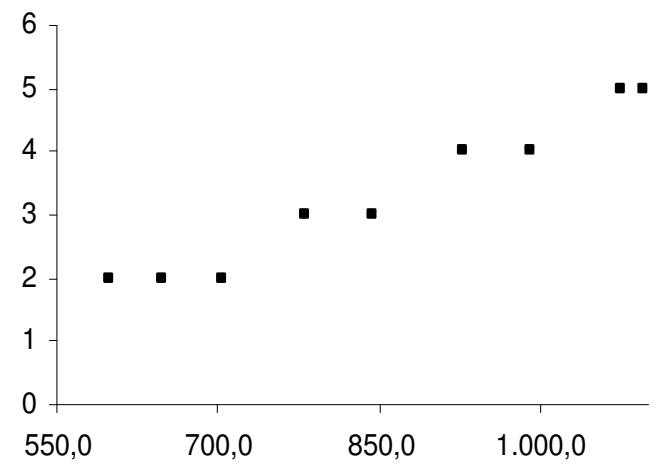

$20 \mathrm{~N}$

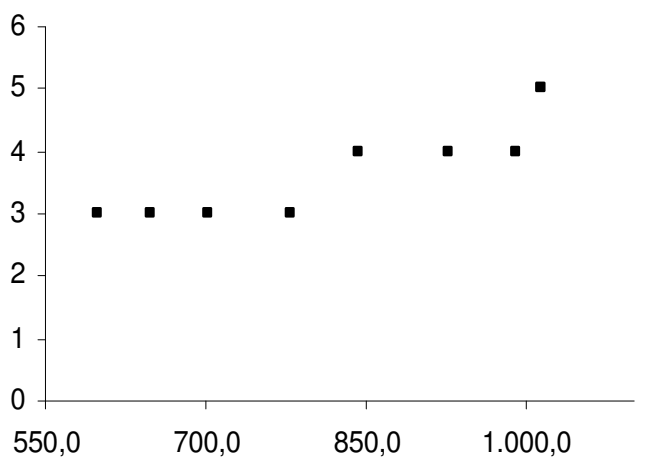

$80 \mathrm{~N}$

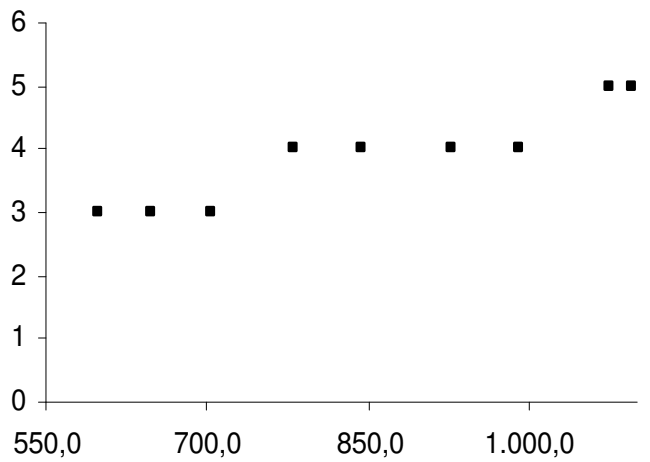

Figura 12. Número de folhas, em função do somatório calórico, do dia 08/07/2005 (1ª medição) ao surgimento do 1ํㅡó para a cultivar BRS 195, nas quatro doses analisadas. 